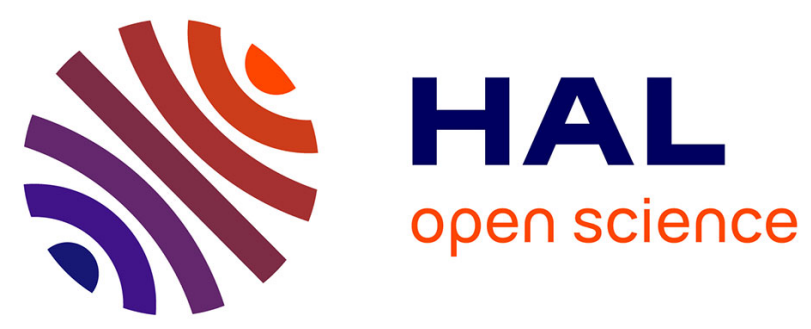

\title{
Experimental study of heterogeneities in strain and temperature fields at the microstructural level of polycrystalline metals through fully-coupled full-field measurements by Digital Image Correlation and Infrared Thermography
}

Laurence Bodelot, Eric Charkaluk, Laurent Sabatier, Philippe Dufrenoy

\section{To cite this version:}

Laurence Bodelot, Eric Charkaluk, Laurent Sabatier, Philippe Dufrenoy. Experimental study of heterogeneities in strain and temperature fields at the microstructural level of polycrystalline metals through fully-coupled full-field measurements by Digital Image Correlation and Infrared Thermography. Mechanics of Materials, 2011, 43 (11), pp.654-670. 10.1016/j.mechmat.2011.08.006 . hal00626385

\section{HAL Id: hal-00626385 \\ https://hal.science/hal-00626385}

Submitted on 15 Jul 2021

HAL is a multi-disciplinary open access archive for the deposit and dissemination of scientific research documents, whether they are published or not. The documents may come from teaching and research institutions in France or abroad, or from public or private research centers.
L'archive ouverte pluridisciplinaire HAL, est destinée au dépôt et à la diffusion de documents scientifiques de niveau recherche, publiés ou non, émanant des établissements d'enseignement et de recherche français ou étrangers, des laboratoires publics ou privés. 


\title{
Experimental study of heterogeneities in strain and temperature fields at the microstructural level of polycrystalline metals through fully-coupled full-field measurements by Digital Image Correlation and Infrared Thermography
}

\author{
L. Bodelot*, E. Charkaluk, L. Sabatier ${ }^{1}$, P. Dufrénoy \\ Laboratoire de Mécanique de Lille, UMR CNRS 8107, Université Lille Nord de France, F-59655 Villeneuve d'Ascq Cedex, France
}

\begin{abstract}
In this paper, we investigate and quantify the thermal effects induced by plastic deformation at the level of the microstructure of a polycrystalline metallic sample. For the first time, this investigation is conducted on a specimen containing hundred of grains. We use a unique experimental setup to access-simultaneously in-situ and in real time-strain and temperature fields of an austenitic stainless steel under tensile loading. We show that strain fields are directly linked to the expression of plasticity at the grain scale. We show, on the other hand, that thermal fields at the last increment of deformation are linked to the microstructural expression of plasticity on a larger lengthscale corresponding, instead, to grain clusters. Hence strain fields exhibit stronger localization features than the temperature fields in terms of both values and space. For a mean temperature rise of $0.75{ }^{\circ} \mathrm{C}$ and a global deformation of $2.4 \%$ in the fastest quasi-static regime investigated in this paper, the maximum local temperature rise is measured to be $0.88{ }^{\circ} \mathrm{C}$ even though local strain in grains can reach up to $6.7 \%$. These fully-coupled measurements also provide the first experimental evidence that an instantaneous coupling takes place within grains between strain gradients and thermal dissipation. Finally, an estimation of a grain-scale field of the fraction of plastic work converted into heat is conducted and shown to be not only heterogeneous but also to be related to the microstructural features of deformation at the surface of the material, namely to the absence or presence of slip bands. The results obtained support the relevance of establishing energy balances and acquiring stored energy data at the microstructural scale where damage localization takes place.
\end{abstract}

\section{Introduction}

It has been long known that plastic deformation of metals causes a temperature change since part of the mechan-

\footnotetext{
* Corresponding author. Present address: California Institute of Technology - GALCIT, 1200 East California Boulevard, Pasadena, CA 91125, United States. Tel.: +1 617899 9395; fax: +1 6264492677.

E-mail addresses: lbodelot@caltech.edu (L. Bodelot), eric.charkaluk@ univ-lille1.fr (E. Charkaluk), laurent.sabatier@lmgc.univ-montp2.fr (L. Sabatier), philippe.dufrenoy@polytech-lille.fr (P. Dufrénoy).

1 Present address: Laboratoire de Mécanique et de Génie Civil - LMGC, UMR CNRS 5508, Université Montpellier II, Place Eugène Bataillon - cc048, 34095 Montpellier Cedex 5, France.
}

ical energy input in the material is dissipated as heat. Unfortunately, this phenomenon has been nearly always observed at the level of a whole specimen. We refer to the first historical calorimetric analyses conducted on metallic bars by Farren and Taylor (1925) and Taylor and Quinney (1933) as well as to studies conducted on single crystals by Rittel et al. (2007). For polycrystals, the emergence of full-field measurement methods like Infrared Thermography (IRT) and Digital Image Correlation (DIC) has given access to finer details, though measurements are still made at the level of the whole gage area of a sample (several square centimeters). In those experiments, IRT and DIC measurements, whether carried out on different 
specimens (Louche, 1999) or on both sides of the same specimen (Chrysochoos et al., 2000; Guduru et al., 2001), showed that localization phenomena were inducing common features of localization for both the strain and temperature fields. Previous results were then analyzed to perform energy balances at the scale of the gage area of the specimens. More recently, the same kind of measurements were conducted at the scale of the gage area (still as big as a few square centimeters) of a bi-crystal modelsample containing only two centimeter-size grains (Saai et al., 2010). In all the energy balances conducted since the first studies of the 1920's, it has been stated that only a part of the mechanical energy is dissipated as heat. The rest, commonly called 'the stored energy of cold work', is considered to change the internal energy of the material. In fact, Stroh (1953) and later Bever et al. (1973) mention a relationship between stored energy and piled-up dislocations, suggesting that thermomechanical phenomena arise at a very fine scale.

Most metals are made of an aggregate of grains (a polycrystal), each with different crystallographic orientations. As a result, even under uniform uniaxial tensile loading, grains are subjected to different stress and strain conditions (Friedel, 1964). Consequently, based on this observation and on the remarks of Stroh (1953), the following question arises: can we find evidence of thermomechanical coupling (i.e. coupling of strain gradient and thermal dissipation) down to the grain level of a polycrystalline sample containing hundreds of grains? This papers aims at experimentally investigating the heterogeneity of the thermal and mechanical fields and aims at establishing a link between the two at the microstructure level of a polycrystalline specimen containing hundreds of grains. This work could be a first step towards the establishment of energy balances at the grain scale and the study of the stored energy at the scale where damage localization takes place.

In the next section, we present an experimental methodology for accessing in-situ fully-coupled full-field measurements at the microstructural scale of polycrystalline materials subjected to mechanical loading. The in-situ aspect of these experiments is crucial if one wants to capture the thermal effects. Thus, emphasis will be put on explaining how to get fully-coupled data. Samples and applied loadings are then described. In the third section, the results obtained are discussed before presenting concluding remarks.

\section{Experimental methods}

The dedicated experimental setup used in this study was partly described in Bodelot et al. (2009). We will briefly recall how to perform strain and temperature measurements at the microstructural scale of a polycrystalline sample and state the performances obtained for both methods in the case of this study. We will thus only focus on explaining how to obtain fully-coupled data by introducing new post-processing features.

\subsection{Local strain measurements at a micrometric scale}

Images of the sample were acquired during loading using a Jai CV-M4+ CCD camera. The camera has a
$1368 \times 1024$ matrix of detectors, each having a size of $6.45 \mu \mathrm{m} \times 6.45 \mu \mathrm{m}$. Since lighting of the object was necessary to obtain contrasted gray scale images of the sample, an optical fiber equipped with an infrared filter was used to ensure a steady and uniform light on the sample while preventing any heat that would interfere with simultaneous thermal measurements. To access the microstructural scale, a high magnification was required. The camera was thusly equipped with a Tamron 23FM50SP $50 \mathrm{~mm}$ lens and extension tubes (35 $\mathrm{mm}$ in total), leading to a spatial resolution of $6.5 \mu \mathrm{m} \times 6.5 \mu \mathrm{m}$ per pixel and a field of view of $8.9 \mathrm{~mm} \times 6.7 \mathrm{~mm}$. Displacement and strain fields were obtained by processing the images by Digital Image Correlation (DIC); the software used in this study was Correli $^{\mathrm{LMT}}$, developed at the 'Laboratoire de Mécanique et Technologie' (LMT) of Cachan in France (Hild, 2002). Briefly, DIC consists of dividing the original image into subsets. Since each subset corresponds to a unique intensity of gray levels, the DIC algorithm detects the new position of a given subset in the deformed image, providing displacement fields and, by differentiation, strain fields. The full details about the principles of the DIC algorithm Correli ${ }^{\mathrm{LMT}}$, capable of sub-pixel accuracy, are fully explained in Hild (2002) and Hild et al. (2002).

Since the DIC computation was performed with $16 \times 16$ pixels subsets, the spatial resolution of the displacement and strain field data was ultimately $104 \mu \mathrm{m} \times 104 \mu \mathrm{m}$. A compromise had to be made here between the resolution that could be achieved and the resulting uncertainty on strain values. Uncertainty for a given speckle and optical configuration was estimated by numerical processing of an image. Correli ${ }^{\text {LMT }}$ software includes a module that numerically generates displaced images from an initial image and then performs DIC on this sequence of images. Since the displacement fields are already known, the average error committed over all the subsets leads to the estimate of the systematic error on displacements. In the same way, since the strain fields derived from the rigid body motions should be null, the average deviation from zero over all the subsets gives the uncertainty on strain data. The relationship between resolution and uncertainty on strain values was then established on an image of the speckle captured in the experimental configuration. The result is plotted in Fig. 1 for different subset sizes (Bodelot, 2008). With a $16 \times 16$ pixels subset, the precision for the measurements in this study were established to be $0.1 \%$ (1000 microstrains).

\subsection{Local temperature measurements at a micrometric scale}

Thermal emission fields were obtained by Infrared Thermography (IRT). The sample was filmed during loading by a Focal Plane Array (FPA) Cedip (now Flir System) Jade III MWIR camera, whose matrix is made of $320 \times 240$ InSb detectors sensitive to the middle infrared wavelength (between 3 and $5 \mu \mathrm{m}$ ).

This camera was used with a G1 high-magnification lens (dedicated to IRT and provided by the camera's manufacturer) where the spatial resolution matches the size of one detector, namely $30 \mu \mathrm{m} \times 30 \mu \mathrm{m}$. This resulted in a field of view of $9.6 \mathrm{~mm} \times 7.2 \mathrm{~mm}$ and a $30 \mu \mathrm{m} \times 30 \mu \mathrm{m}$ resolution for the infrared fields data. 


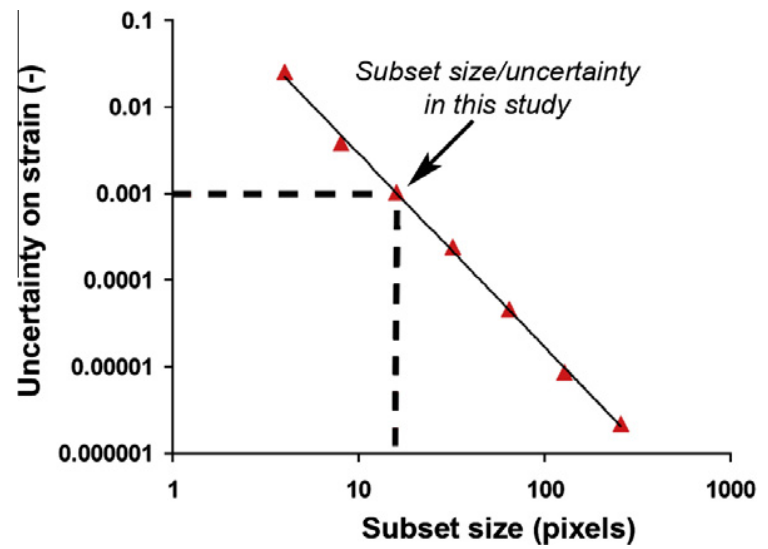

Fig. 1. Evolution of the uncertainty on strain values as a function of the subset size used for DIC computation. Analysis is done on images of the speckle used in this study captured in experimental conditions (Bodelot, 2008).

Before obtaining temperature data, the link between the infrared radiation received by the camera and the temperature of the object needed to be established through a calibration procedure. Given the fact that each detector of an FPA camera has its own behavior, standard procedures take this non-uniformity into account by correcting the response of each detector and bringing it close to the array mean response. Then, when linking the mean temperature of a reference source (often a blackbody) to the array mean response, all pixels are calibrated at once. The advantage is to have a single calibration curve valid for all pixels. In most applications, where the field of view is relatively large, this method is generally sufficient. Nevertheless, this technique is not satisfactory when it comes to measuring temperature gradients over a few pixels as was required in this study. Thus the camera was calibrated using a so-called 'pixel by pixel calibration'. As opposed to considering the average value over the whole matrix, the link between the received infrared radiation and the temperature of the object was determined for each detector. Details about this specific calibration of the camera enabling temperature measurements at a microscopic scale can be found in Bodelot et al. (2009). We emphasize that the calibration of the camera was made in the exact configuration in which it was used during the in-situ experiments (including the dichroic mirror) so as to keep the same optical path. As a result of this calibration, the temperature measured by each detector was established from the infrared data and the final temperature fields were obtained after a smoothing of the field over a $3 \times 3$ pixel window. In the end, the spatial resolution of the temperature fields was $90 \mu \mathrm{m} \times 90 \mu \mathrm{m}$. In this study, the precision of the temperatures measured by the infrared detectors of the whole matrix was established to be $27.6 \mathrm{mK}$ on average with a standard deviation of $6.8 \mathrm{mK}$ (Bodelot, 2008).

\subsection{In-situ coupled observation of the same area}

The above mentioned techniques are usually used separately to obtain strain and temperature fields at a very fine scale. The goal of this work, however, was to perform fullycoupled measurements (i.e. at the same time and in the same area) in order to get data related to a given microstructure. In other studies, these fields could be obtained from different samples (Louche and Chrysochoos, 2001) or from different faces of the same sample (Guduru et al., 2001). But in this study, since the microstructure is different from one location on the sample to another (and hence from one face to the other one), the same area of the sample gage zone needed to be observed by both cameras while taking into account the fact that both arrays of detectors had to remain parallel to the image of the sample surface. As a matter of fact, considering the magnification used in this study, the CCD camera's axis could not deviate from the sample surface normal without losing focus on part of the sample. Had the axis deviated, distortions would have been introduced in the measured fields or, even worse, DIC might have been unsuccessful. For the infrared camera, even though a slight deviation of its axis from the normal to the sample surface is considered acceptable at a larger scale (Saai et al., 2010), conducting high-precision temperature measurements at a micrometric scale using a 'pixel by pixel calibration' required the infrared sensor to be strictly parallel to the sample. Two arguments derived from the fundamentals of Infrared Thermography supported this statement. Consider the equation of the total thermal flux $\Phi$ received by the camera

$\Phi=\tau_{a t m}\left[\varepsilon_{o b j} \Phi_{o b j}+\left(1-\varepsilon_{o b j}\right) \Phi_{e n v}\right]+\left(1-\tau_{a t m}\right) \Phi_{a t m}$,

where $\tau_{a t m}$ is the transmission of the atmosphere, $\varepsilon_{o b j}$ the emissivity of the object, and $\Phi_{o b j}, \Phi_{e n v}, \Phi_{a t m}$ are the thermal fluxes radiated by the object, the environment and the atmosphere, respectively. Since the atmosphere intervenes in the thermal flux $\Phi$ received by the camera, keeping the sensor parallel to the sample ensures an identical effect from the atmospheric transmission at any point of measurement. Furthermore, the apparent emissivity is known to decrease as the angle of observation with the normal to the sample increases. This problem has been widely addressed in aerial thermography measurements (Sobrino and Cuenca, 1999), due to the unavoidable constraints inherent in this domain. It is rarely mentioned in laboratory mechanical experiments (Horny, 2003), since experimental setups are usually arranged in such a way so that the infrared sensor is strictly parallel to the object (Berthel et al., 2007, 2008; Guduru et al., 2001). Knowing that the emissivity of any coating is always lower than the ideal unitary emissivity of the black body, one cannot afford an even lower emissivity when the goal is to minimize the influence of the environment as it appears in Eq. (1).

Thus in our case, to achieve a fully-coupled observation of the same zone while getting optimal conditions to ensure accurate measurements, a dichroic mirror was placed in front of the sample at an angle of $45^{\circ}$ with the surface normal. Due to its filtering properties, the dichroic mirror transmitted the full infrared radiation (wavelengths between 2 and $6 \mu \mathrm{m}$ ) towards the infrared camera which was located in front of the sample. The mirror reflected the rest of the radiation, including the visible radiation, 


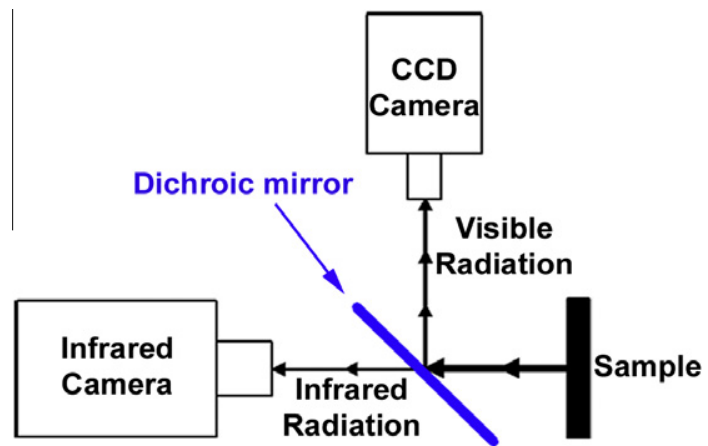

Fig. 2. Schematic of the fully-coupled observation. Since the dichroic mirror makes an angle of $45^{\circ}$ with the normal to the sample surface, both arrays of detectors remain parallel to the image of the sample surface while simultaneously observing the same area.

to the CCD camera which was perpendicular to the normal of the sample (Fig. 2). Additionally, a trigger box sending TTL signals simultaneously to both cameras and the machine acquisition device, enabled us to start both acquisitions at the same moment.

\subsection{Coupled in-situ measurements on the same area}

This fully-coupled observation of the same zone by both the CCD and the infrared cameras, thanks to the dichroic mirror, was a first step towards our objective. However, the keystone of the fully-coupled measurements lied in the coating applied on the sample. As a matter of fact, this coating had to be suitable for both techniques at the same time for the high magnifications used. On the one hand, it had to exhibit a speckle aspect at a very fine scale covering a wide range over the gray scale, as required for the DIC computation. On the other hand, to perform IRT, the coating needed a high and uniform emissivity at the working scale as close as possible to that of the blackbody used for calibration.

Certain tests that we conducted revealed that classically used coatings such as high emissivity black spray paint or black and white spray paint speckles, failed to be suitable for both aforementioned requirements at the considered scale. As a result, a special coating was designed to meet these requirements at the same time for the magnifications used (Bodelot, 2008). When observed by the CCD camera equipped with the $50 \mathrm{~mm}$ lens and the two extension tubes, the coating revealed a speckle aspect covering a large range over the gray scale. This enabled us to perform DIC with relatively small subsets (Fig. 3a) while keeping the emissivity high and uniform for observations by the infrared camera equipped with the G1 lens (Fig. 3b). The emissivity of the coating was established (in the presence of the dichroic mirror) in Bodelot (2008) and had an average value of 0.927 , taken into account during the conversion from thermal emission to temperature.

Since no measurements could have been done without a coating of some kind, the developed coating was made of metallic powders, providing several advantages in the context of this high-resolution study. The powders were applied by airbrush which enabled us, by successive strokes, to reach a fully covering coat with a minimum thickness. Hence we were at least able to minimize any possible effects of the thickness of our coating at the scale of observation when compared to a much thicker and more common paint coating, for example. Additionally, as opposed to polymeric paints commonly used in the infrared measurement community, this coating naturally ensured a better conductivity of the underlying substrate temperature-thus reducing possible thermal filtering effects, if any. Moreover, though the effects of coatings on the mechanisms of deformation measured by DIC have not been addressed, even for studies conducted at the grain level (Saai et al., 2010; Badulescu et al., 2011), the fact that our coating was made of powder minimized any interaction with local mechanisms (such as the emergence of slip lines) when compared to cohesive coatings like paint.

\subsection{Final coupling of the data}

While strain fields obtained by DIC are expressed in the undeformed configuration, thermal fields are those of a deforming body. In other words, IR detectors give the temperature of material points moving in front of them, an impediment to a straightforward superimpositionand thus comparison-of the obtained strain and temperature fields. To follow the temperature of a given material point, its displacement in front of the infrared array has to be known. To solve this problem, we needed to use the DIC displacement data to track the displacement of material points in front of the infrared array, thus making it possible to express the temperature fields in the undeformed configuration (Bodelot, 2008). However, in our experimental setup, both cameras could not observe
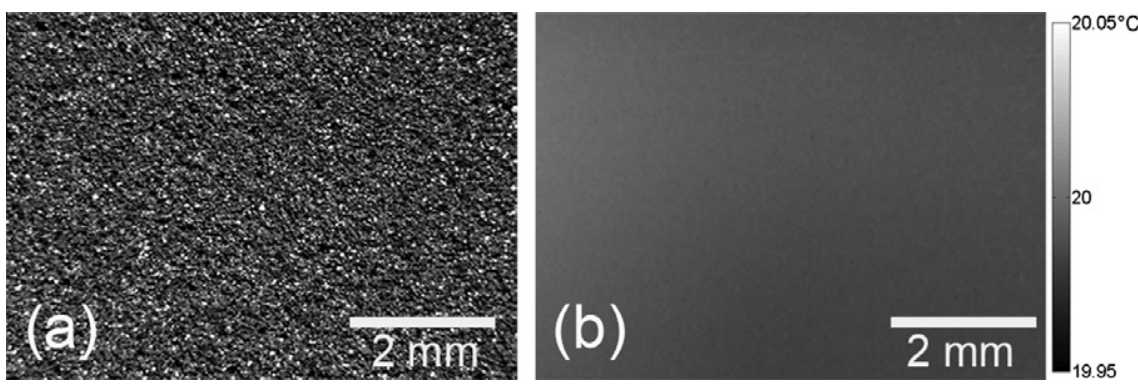

Fig. 3. Observation of the coating specially designed for the study (a) by the CCD camera equipped by the $50 \mathrm{~mm}$ lens and extension tubes and (b) by the infrared camera equipped with the G1 lens. 
exactly the same zone nor could they possess exactly the same magnification. Thus a first step was to establish the transformation between the two coordinate systems. Letting $P_{\mathrm{CCD}}(X, Y)$ denote a point in the coordinate system of the CCD camera and $P_{\mathrm{IR}}(\xi, \eta)$ denote a point in the infrared camera coordinate system, the transformation from the infrared camera coordinate system to the CCD camera coordinate system involved a translation, a rotation and a rescaling, respectively given as

$P_{\mathrm{CCD}}\left(\begin{array}{l}X \\ Y\end{array}\right)=R\left(\begin{array}{ll}a_{11} & a_{12} \\ a_{21} & a_{22}\end{array}\right) \times P_{\mathrm{IR}}\left(\begin{array}{l}\xi \\ \eta\end{array}\right)+T\left(\begin{array}{l}b_{1} \\ b_{2}\end{array}\right)$,

where the coordinates $X, Y, \xi$ and $\eta$ in their corresponding space were taken at the center of the pixels. The inverse transformation from the CCD camera coordinate system to that of the infrared camera was then given by

$P_{\mathrm{IR}}\left(\begin{array}{c}\xi \\ \eta\end{array}\right)=R^{-1} \times\left[P_{\mathrm{CCD}}\left(\begin{array}{l}X \\ Y\end{array}\right)-T\right]$.

Determining the coefficients matrices $R$ and $T$ of the plane transformation required identifying 3 points on both the optical and infrared images that corresponded to identical material points. For that purpose, three indentation-like marks were placed on the sample prior to the experiments. These marks were far from the analyzed zone defined in Section 2.6 but were still visible on the edges of the initial images taken by both cameras just before the start of the loading. Once $R$ and $T$ were known, the algorithm (see diagram in Fig. 4) began by associating each pixel $P_{\mathrm{IR}, 0}$ of the initial infrared image to its counterpart $P_{\mathrm{CCD}, 0}$ in the initial CCD image using Eq. (2). Given the displacement data from the DIC computation, we then determined the position of the pixel $P_{\mathrm{CCD}, i}$ at each instant $t_{i}$ of the loading relative to its initial position $P_{\mathrm{CCD}, 0}$. At each $t_{i}$, Eq. (3) gave the position $P_{\mathrm{IR}, i}$ of the corresponding infrared point. As a result, for each material point located in front of the infrared detector $P_{\mathrm{IR}, 0}$ at the initial instant, we made it known, at each instant $t_{i}$, the detector $P_{\mathrm{IR}, i}$ corresponding to the same material point. This finally enabled us to reconstruct an infrared movie where the material points were fixed.

The data presented in this article are hence fullycoupled insofar as both fields are expressed in the undeformed configuration (Lagrangian description) and correspond to the same zone at the same time. The experimental principles and the data processing presented thus far were finally combined to conduct and analyze the two experiments described in the next section.

\subsection{Material, samples and loadings}

The material of interest was an AISI 316L austenitic stainless steel. Dog-bone shaped flat samples $2 \mathrm{~mm}$ thick (Fig. 5) were heat treated under air for $2 \mathrm{~h}$ at $1200^{\circ} \mathrm{C}$ and immediately water-quenched. They were mechanically polished up to a $1 \mu \mathrm{m}$ diamond finish on the studied face, and up to $4000 \mathrm{SiC}$ paper on the opposite face and on the edges. The mean grain size of the heat-treated material was $125 \mu \mathrm{m}$ with a standard deviation of $113 \mu \mathrm{m}$ when twin boundaries were taken into account (via the line intercept method). When twin boundaries were neglected, the average grain size was $237 \mu \mathrm{m}$ with a deviation of $159 \mu \mathrm{m}$. Grains were thus generally larger than the spatial resolution capabilities of both techniques. This meant that the spatial resolutions achieved in strain and temperature
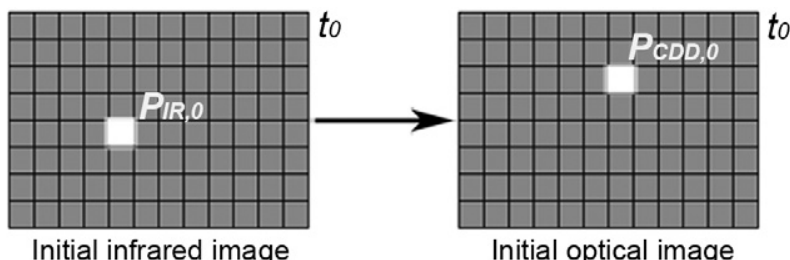

Initial optical image I

displacement data
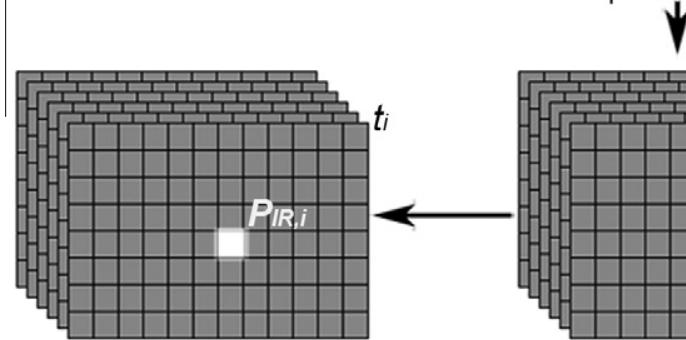

Positions of $P_{I R, 0}$ over the test<smiles>[AlH2][VH2]</smiles>

Infrared movie in the reference configuration

Fig. 4. Principle of the algorithm used to follow material points in front of the infrared sensor and express the infrared fields in the undeformed configuration. 


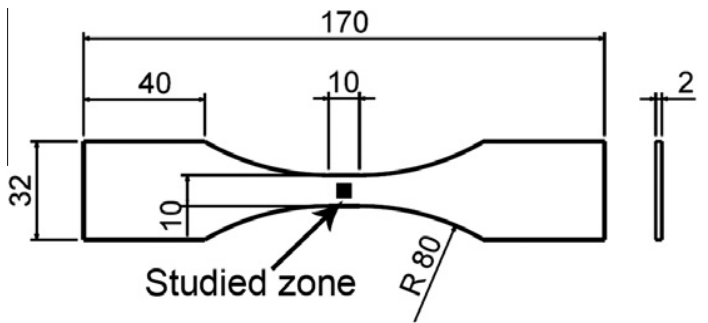

Fig. 5. Dimensions (in millimeters) of the samples used in this study and position of the $5 \mathrm{~mm} \times 5 \mathrm{~mm}$ zone of interest (ZOI).

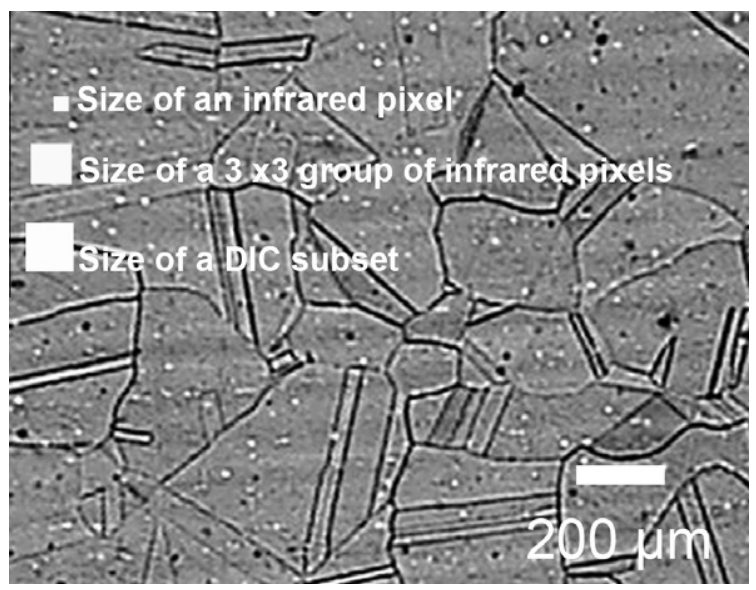

Fig. 6. Sizes of an infrared pixel, a group of $3 \times 3$ infrared pixels and a DIC subset overlaid on the microstructure of the heat-treated material, emphasizing that resolutions give data at the sub-grain level.

measurements were suitable to give meaningful data at the scale of the grains of the studied material (see Fig. 6).

The presented strain and temperature fields are those of a common central $5 \mathrm{~mm} \times 5 \mathrm{~mm}$ zone of interest (ZOI) located in the center of the gage area (Fig. 5). This central zone is positioned in such a way that the indentation-like marks used for establishing the plane transformation (see Section 2.5) are as far away from it as possible, ensuring no interaction of those marks with the response of the ZOI. Focusing on this central zone of the obtained full-field data also guarantees elimination of any edge effects.

The tests presented in this article were performed on an electro-mechanical Instron 4508 machine. A picture of the machine with the dedicated experimental setup developed for in-situ fully-coupled strain and temperature full-field measurements is presented in Fig. 7. All the elements of the setup are covered with black paint or black fabric, and the whole setup is protected from the surroundings by black cartons in order to minimize thermal reflections and thermal flux with the surrounding environment. These precautions are taken to offer optimum conditions for precise thermal measurements with the infrared camera (Bodelot, 2008). Two quasi-static tensile tests were carried out at room temperature and at two different constant crosshead speeds (i.e. displacement controlled mode). The crosshead speeds were converted into equivalent average strain rates; the equivalent strain rate of the first test was $5 \times 10^{-4} \mathrm{~s}^{-1}$ and of the second was $5 \times 10^{-3} \mathrm{~s}^{-1}$. Tests were conducted up to a maximum nominal stress of $270 \mathrm{MPa}$ in both cases.

\section{Results and discussion}

\subsection{Global data extracted from the fields}

The fields of variation of temperature from initial equilibrium and the axial strain fields (i.e. strain fields in the loading direction) were averaged over the $5 \mathrm{~mm} \times 5 \mathrm{~mm}$ ZOI and are plotted versus time for both strain rates in Fig. 8. Included is the applied nominal stress to the sample that corresponds to the force measured by the load cell divided by the initial section in the gage area. For the rest of the article, any 'average' value of strain and temperature is obtained by averaging the results from DIC and IRT, respectively, over the $5 \mathrm{~mm} \times 5 \mathrm{~mm}$ ZOI.

The $0.2 \%$ yield stress is $200 \mathrm{MPa}$ for the test at $5 \times 10^{-4} \mathrm{~s}^{-1}$ and $223 \mathrm{MPa}$ for the one at $5 \times 10^{-3} \mathrm{~s}^{-1}$. Compared to the $0.2 \%$ yield stress of $261 \mathrm{MPa}$ given for standard $316 \mathrm{~L}$ steel, these values account for a softening of the (a)

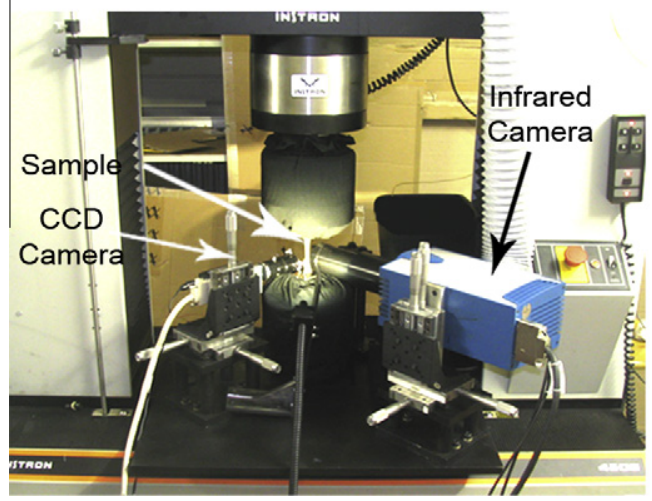

(b)

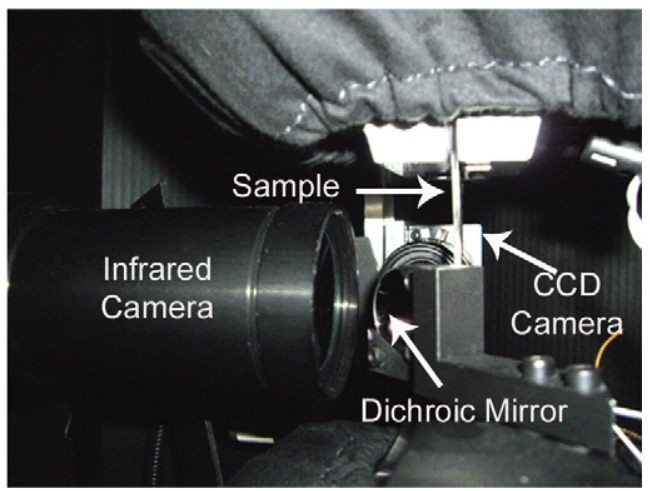

Fig. 7. (a) Picture of the experimental setup developed for fully-coupled strain and temperature full-field measurements and (b) zoom in the area next to the sample. 

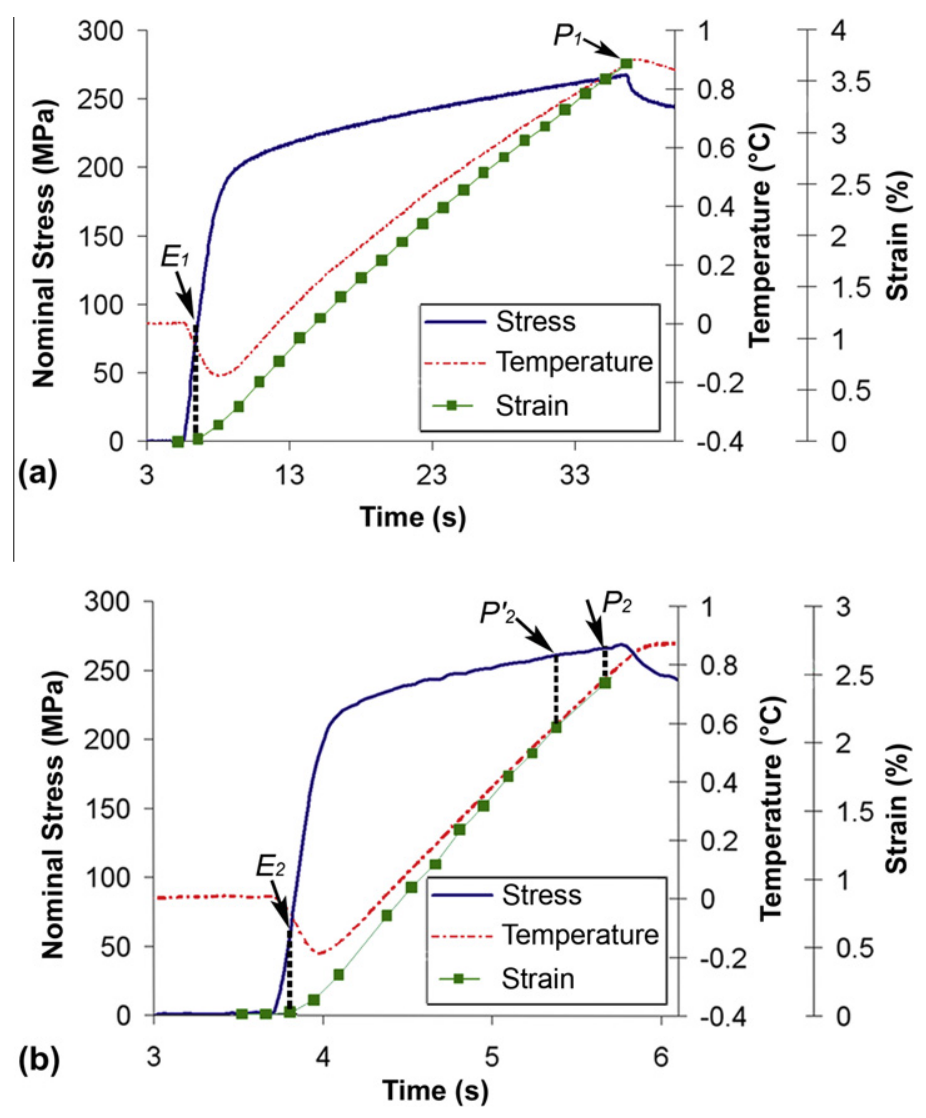

Fig. 8. Evolution of the nominal stress, the mean value of the fields of variation of temperature from initial equilibrium over the $5 \mathrm{~mm} \times 5$ mm ZOI and the mean value of the axial strain fields over the $5 \mathrm{~mm} \times 5 \mathrm{~mm}$ ZOI. (a) Test at $5 \times 10^{-4} \mathrm{~s}^{-1}$ and (b) test at $5 \times 10^{-3} \mathrm{~s}^{-1}$.

material caused by the heat treatment. Moreover, the maximum axial strain reached in the case of the test at $5 \times 10^{-4} \mathrm{~s}^{-1}$ (3.68\%) is higher than the one reached in the case of the test conducted at $5 \times 10^{-3} \mathrm{~s}^{-1}(2.42 \%)$. The effect of the strain rate on the material strain hardening is thus non-negligible. At the beginning of both tests, the drop in the average values of the fields of variation of temperature from initial equilibrium over the $5 \mathrm{~mm} \times 5 \mathrm{~mm}$ $\mathrm{ZOI}$ is due to the thermoelastic effect. This effect makes the sample temperature drop linearly under elastic tension and rise linearly under elastic compression. After this initial drop, the temperature of the ZOI increases as a state of global plastic deformation is reached.

\subsection{Evolution of the strain and temperature variation fields in the elastic-plastic transition}

We now discuss the data obtained at the microstructural level. For both tests, we present the axial strain fields as well as the corresponding fields of variation of temperature from the initial equilibrium for one instant in the global elastic regime and one instant in the global plastic regime. Those instances are respectively denoted $E_{1}\left(E_{2}\right)$ and $P_{1}\left(P_{2}\right)$ for the test at $5 \times 10^{-4} \mathrm{~s}^{-1}\left(5 \times 10^{-3} \mathrm{~s}^{-1}\right)$ on the curves of Fig. 8a (Fig. 8b). Data corresponding to the $5 \times 10^{-4} \mathrm{~s}^{-1}$ test is presented in Fig. 9, and data corre- sponding to the $5 \times 10^{-3} \mathrm{~s}^{-1}$ test is presented in Fig. 10 . In addition, histograms of distributions of strains and temperature values over the $5 \mathrm{~mm} \times 5 \mathrm{~mm}$ ZOI fields in Figs. 9 and 10 are presented in Figs. 11 and 12, respectively.

Each of the strain fields (a) and (b) in both Figs. 9 and 10 exhibit heterogeneities through local gradients that become stronger as the applied stress increases from 84.3 MPa to $267.5 \mathrm{MPa}$ (between instants $E_{1}$ and $P_{1}$ ) for the $5 \times 10^{-4} \mathrm{~s}^{-1}$ test and from 58.9 MPa to $268.6 \mathrm{MPa}$ (between instants $E_{2}$ and $P_{2}$ ) for the $5 \times 10^{-3} \mathrm{~s}^{-1}$ test. In the elastic fields of Figs. 9a and 10a, a non-negligible part of the values are within the experimental uncertainty, established to be $0.1 \%$. Nonetheless, values higher than $0.5 \%$ in both cases demonstrate an early appearance of plastic deformation, even though both samples are under a load that gives rise to global elastic deformation (as it can be seen from the position of $E_{1}$ and $E_{2}$ on the stress curves in Fig. 8). This appearance of early local plasticity is accounted for by the fact that grains within the polycrystal possess different orientations and neighbors (Osterstock et al., 2007; Sauzay, 2006). When uniform tensile loading is applied to the sample, grains are subjected to different resolved shear stresses according to their orientations. This explains why some grains can locally yield while others are still in the elastic regime. For strain fields related to a load that gives rise to global plastic deformation (Figs. 9b and 


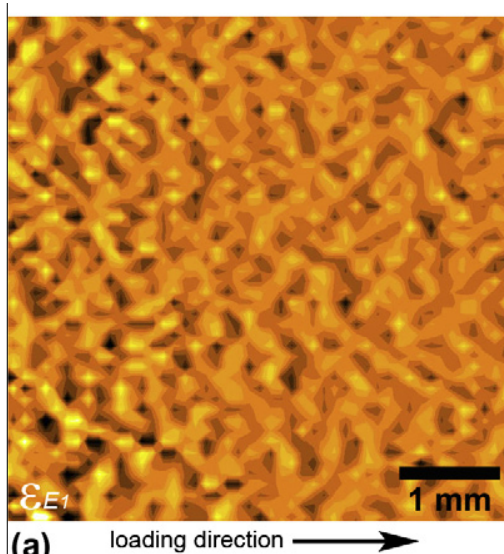

(a)

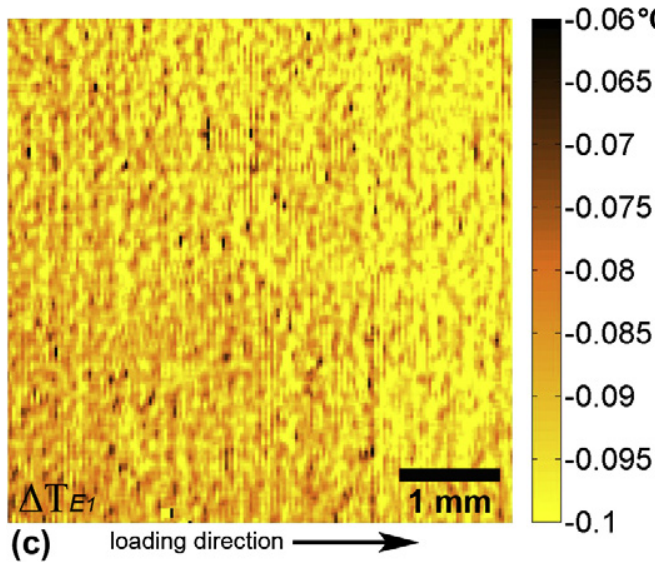

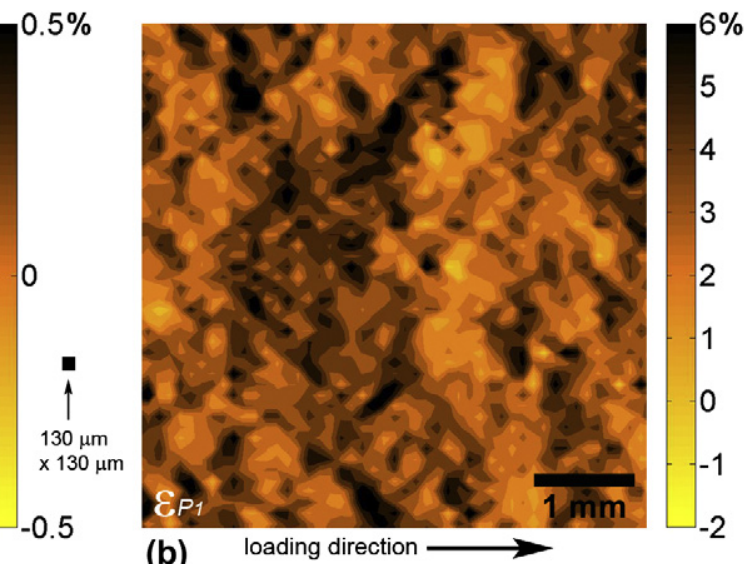

(b)

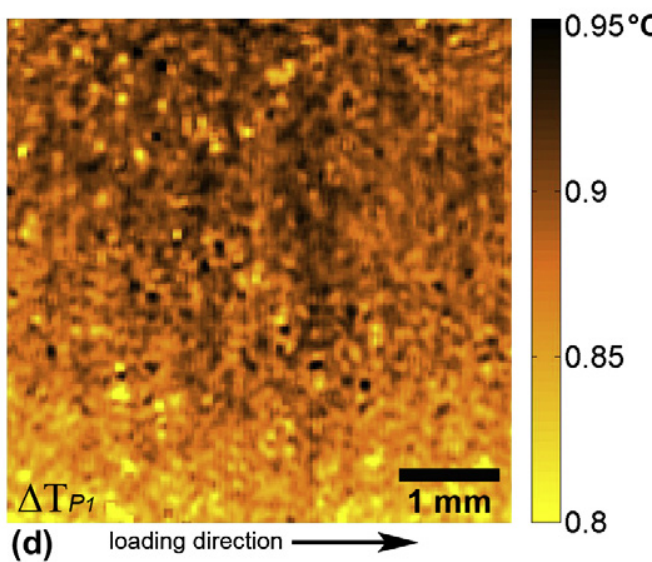

Fig. 9. Case of the $5 \times 10^{-4} \mathrm{~s}^{-1}$ test. Axial strain fields in the loading direction over the $5 \mathrm{~mm} \times 5 \mathrm{~mm}$ ZOI at instants (a) $E_{1}$ under global elastic regime and (b) $P_{1}$ under global plastic regime. Fields of variation of temperature from the initial equilibrium to instants (c) $E_{1}$ and (d) $P_{1}$.

10b), strain values are definitely above the measurement uncertainty. Strain gradients are also larger and less scarce than under global elastic deformation. Moreover, high and low values of strain tend to aggregate over the fields, but the strain fields still have a strong heterogeneous aspect. In all strain fields presented in Figs. 9 and 10, negative axial strain values reveal that some grains of the polycrystal are in a contraction state while the sample is submitted to a global tensile loading. The stress and strain to which a grain is subjected is directly related to its orientation. When this grain is part of a polycrystalline aggregate, its response is strongly dependent on the behavior of its neighbors (Jaoul, 1965; Sauzay, 2006). This means that under the influence of neighboring grains, some grains can undergo contraction so that the whole polycrystal can accommodate the global deformation to which it is subjected. It could also be possible that some grains are already in a pre-compression state prior to loading as a result of material processing. However, in our case, the heat treatment performed is very likely to have relieved all the residual stresses of the material. The existence of this phenomenon has already been noticed: compressive values appeared in the residual strains measured after tensile loading by Macherauch (1966) and, more recently, by Efstathiou et al. (2010). Negatives values were also mea- sured experimentally by DIC during the tensile part of a cyclic loading conducted by El Bartali et al. (2007), and were also accounted for numerically in the simulation of a polycrystalline aggregate (Evrard et al., 2010). Even though the loading is uniform, the heterogeneous response of the polycrystal at the local scale is linked to the intrinsic heterogeneity of crystallographic orientations within the aggregate. This kind of behavior can also be related to granular materials, where the same phenomena stem from the microstructural disorder of the granular assembly. As a result, localization at the microstructural scale (Bagi, 1996), early appearance of plasticity (Goldenberg and Goldhirsch, 2002), and influence of the neighbors (Walsh et al., 2007) have long been observed in this domain. This explains the systematic integration of the influence of the microstructures in constitutive models (Lance and Nemat-Nasser, 1986; Ostoja-Starzewski, 1993; Nicot et al., 2005).

As far as the variation of temperature from the initial equilibrium is concerned, the two fields in Figs. 9c and 10c exhibit negative values, indicating a cooling when the sample is under a global elastic state. This can be attributed to the thermoelastic effect described earlier. Both fields, through their gradients, reveal the heterogeneous aspect of the cooling within the polycrystal. From 

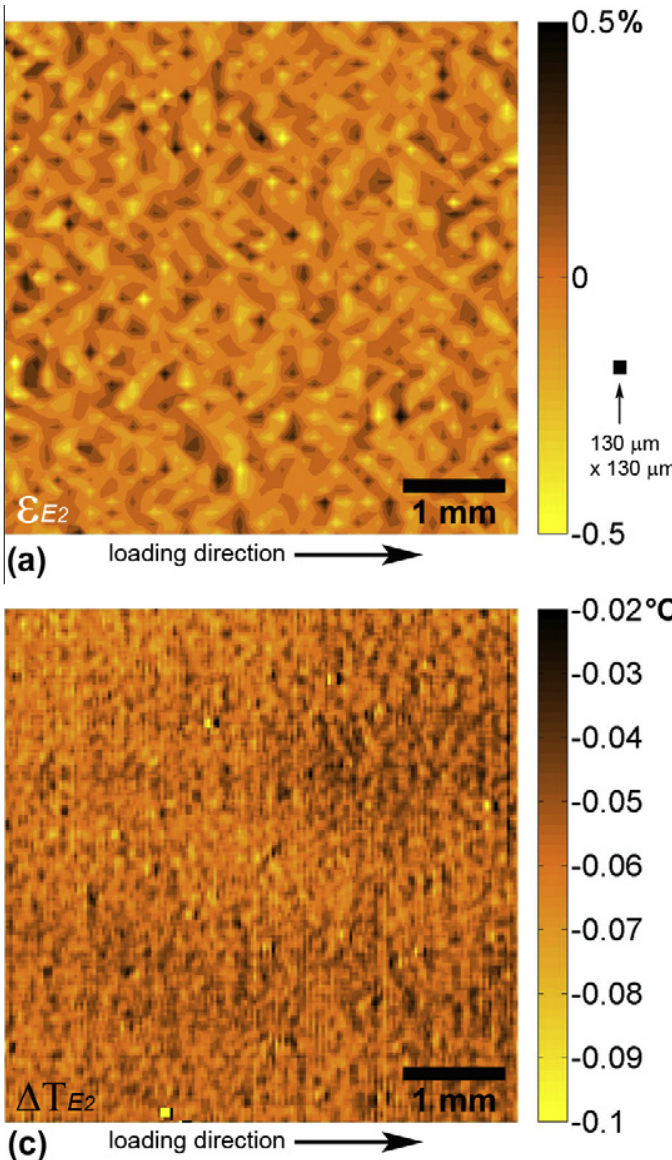
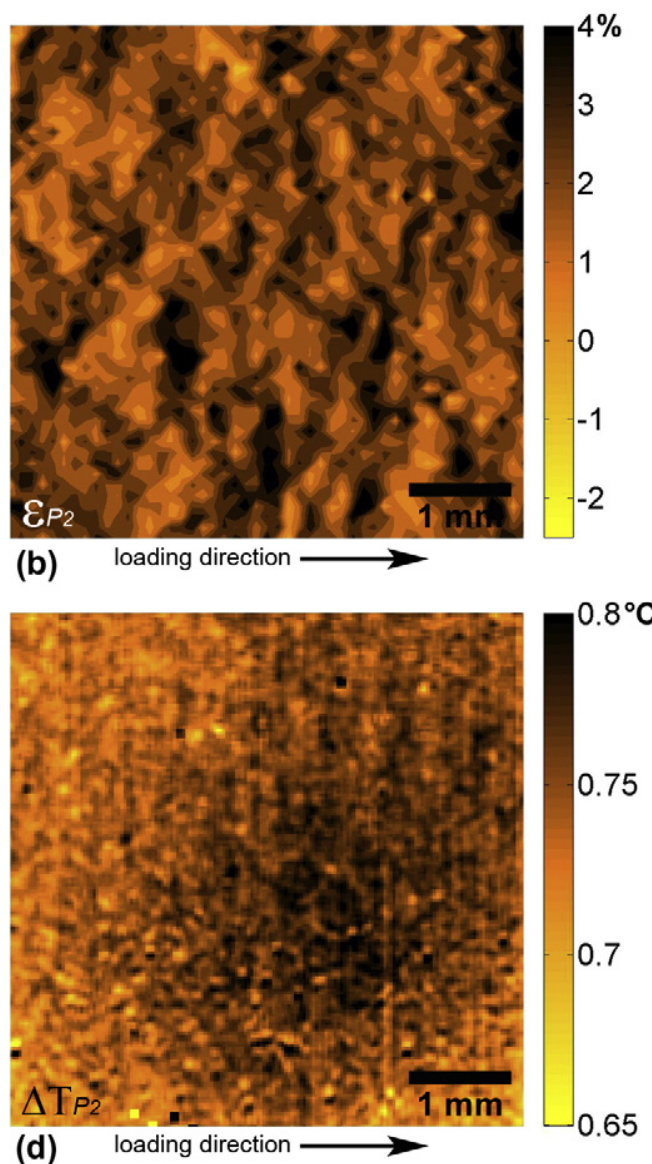

Fig. 10. Case of the $5 \times 10^{-3} \mathrm{~s}^{-1}$ test. Axial strain fields in the loading direction over the $5 \mathrm{~mm} \times 5 \mathrm{~mm}$ ZOI at instants (a) $E_{2}$ under global elastic regime and (b) $P_{2}$ under global plastic regime. Fields of variation of temperature from the initial equilibrium to instants (c) $E_{2}$ and (d) $P_{2}$.

the existence of localized plasticity at this stage of the loading (see the strain fields (a) in Figs. 9 and 10), one can assume that this heterogeneity among the negative values comes from the fact that some grains are currently dissipating, thus inverting the drop due to thermoelasticity and hence the 'cooler' measured values. Though we do not present any plots here for the sake of brevity, we have noticed that thermal fields measured a little later in the loading-at the beginning of yielding-reveal the co-existence of negative and positive values of temperature variations among the grains in the ZOI. This means that at this stage, some grains have dissipated enough to compensate for the drop due to thermoelasticity, while others have not experienced enough plasticity yet to produce a thermal dissipation. At instants $P_{1}$ and $P_{2}$, respectively (when global plasticity has been long reached), fields in both Figs. 9d and 10d correspond to positive values of the temperature gradient, a sign of plastic thermal dissipation in all grains of the polycrystal. Even though every grain is dissipating, the thermal fields remain heterogeneous, revealing that the dissipation rate is different among the grains. Nonetheless, the clusters of high and low values are much wider and more diffused than what can be observed on the strain fields corresponding to the same instance. We also notice that the gradients measured over the ZOI are much smaller in the case of $5 \times 10^{-4} \mathrm{~s}^{-1}$; as a matter of fact, the whole scale covers $0.15^{\circ} \mathrm{C}$ in Fig. $9 \mathrm{~d}$ and $0.25^{\circ} \mathrm{C}$ in Fig. $10 \mathrm{~d}$. This fading (or smoothing) of the gradients appears in the slowest test because the thermal diffusion leaves more time for the material to conduct the temperature This link between strains (elastic and plastic), dissipation and energy storage can be related to common knowledge in the field of granular materials as discussed by Collins (2005) and Nicot and Darve (2006). Additionally, the thermal fields show that heterogeneous thermal events also appear early under a load that gives rise to global elastic deformation. Like in polycrystalline metals, global temperature changes in granular materials come from heat dissipation that occurs at the local scale although, in this case, they are due to small slides in the inhomogeneous force chains between particles (Kruyt and Rothenburg, 2006; Wang et al., 2007).

To give a more quantitative analysis of the fields presented in Figs. 9 and 10, their corresponding histograms are plotted in Figs. 11 and 12. For both tensile tests, the average values $\left(\varepsilon_{\mathrm{avg}}\right)$, their standard deviations $\left(\varepsilon_{\mathrm{std}}\right)$, and the local minima $\left(\varepsilon_{\min }\right)$ and maxima $\left(\varepsilon_{\max }\right)$ of the elastic and plastic strain fields are reported in Table 1 . Values concerning the variation of temperature compared to the initial equilibrium are reported in Table 2 . For both cases of 

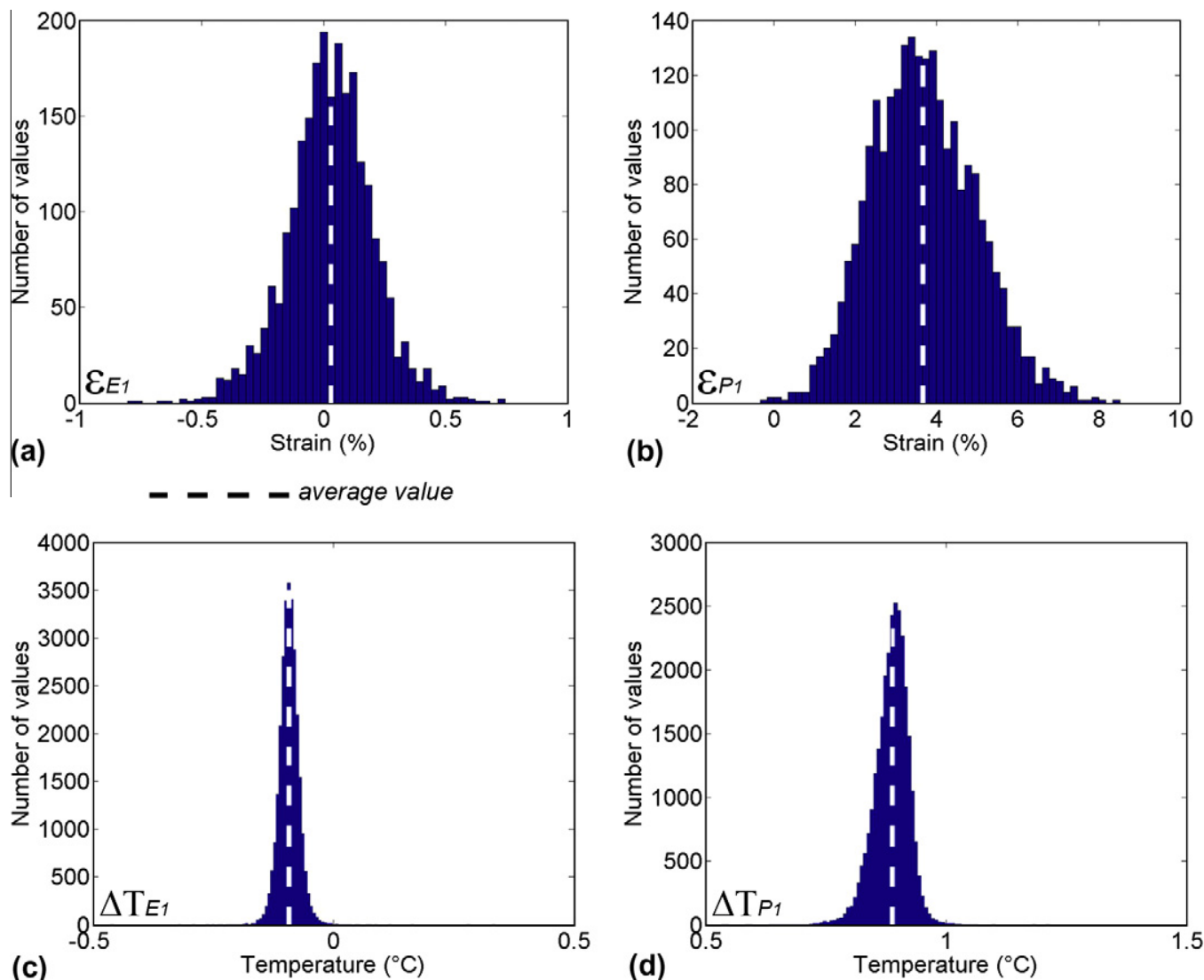

Fig. 11. Case of the $5 \times 10^{-4} \mathrm{~s}^{-1}$ test. Histograms of distribution of strains values over the $5 \mathrm{~mm} \times 5 \mathrm{~mm}$ fields at instants (a) $E_{1}$ under global elastic regime and (b) $P_{1}$ under global plastic regime. Histograms of distribution of temperature variation values over the $5 \mathrm{~mm} \times 5 \mathrm{~mm}$ fields at instants (c) $E_{1}$ and (d) $P_{1}$.

strain values under global elastic deformation, the average value is very small with a fairly even distribution of negative and positive values. As the sample is submitted to a load that gives rise to a global plastic deformation, the distribution is shifted towards higher values (and hence a higher average) leaving only a few negative values. This means that the amount of grains under contraction is high under global elastic deformation but negligible under global plastic deformation. For the two tests, the local strains can reach very high values that are more than twice the average strain measured on the whole ZOI. One notices that the ratio $\varepsilon_{\text {std }} / \varepsilon_{\text {avg }}$ is high under global elastic deformation and diminishes as global plasticity develops (see Table 1). It thusly appears that although the strain fields are heterogeneous at the grain level throughout the whole deformation, the degree of relative heterogeneity at the local scale is higher under global elastic deformation than it is under global plastic deformation. The analysis of the data obtained during both tests thusly confirms a comment made about the deformation mechanisms of polycrystals (Lemaitre and Chaboche, 1988), in which both the crystal rotation and the activation of multiple slip systems (necessary to ensure the deformation compatibility) lead to 'homogenization' of the deformation in generalized plasticity. Nevertheless, even if the dispersion of strain values at the grain level fades with generalized plasticity, the
Taylor assumption-which states that the plastic strain is equal in each grain and identical to the macroscopic plastic strain (Taylor, 1938)-remains a poor assumption of the actual behavior of the polycrystal. For the temperature gradients, the ratio $\Delta T_{\text {std }} / \Delta T_{\text {avg }}$ (where $\Delta T_{\text {std }}$ and $\Delta T_{\text {avg }}$ are respectively the standard deviation and the average value over the $5 \mathrm{~mm} \times 5 \mathrm{~mm} \mathrm{ZOI}$ ) also drops between $E_{1}$ and $P_{1}$ for the $5 \times 10^{-4} \mathrm{~s}^{-1}$ test and between $E_{2}$ and $P_{2}$ for the $5 \times 10^{-3} \mathrm{~s}^{-1}$ test (see Table 2). This indicates a drop in the level of dispersion of temperature gradient values between the global elastic state and the plastic one.

\subsection{Post-loading micrographs}

After the tensile loading, the coating of the sample is removed by thoroughly washing it with acetone and plunging it into an ultrasonic bath containing first acetone and then alcohol. During the cleaning, care is taken to avoid any contact or scratches to the surface of the sample. Pictures of the deformed sample are taken by an Olympus PMG3 microscope and then assembled together to give overall post-mortem micrographs of each $5 \mathrm{~mm} \times 5 \mathrm{~mm}$ ZOI (Fig. 13).

These micrographs underline the heterogeneous nature of the deformation at the grain scale. Some grains show heavily marked parallel lines (an example is highlighted 

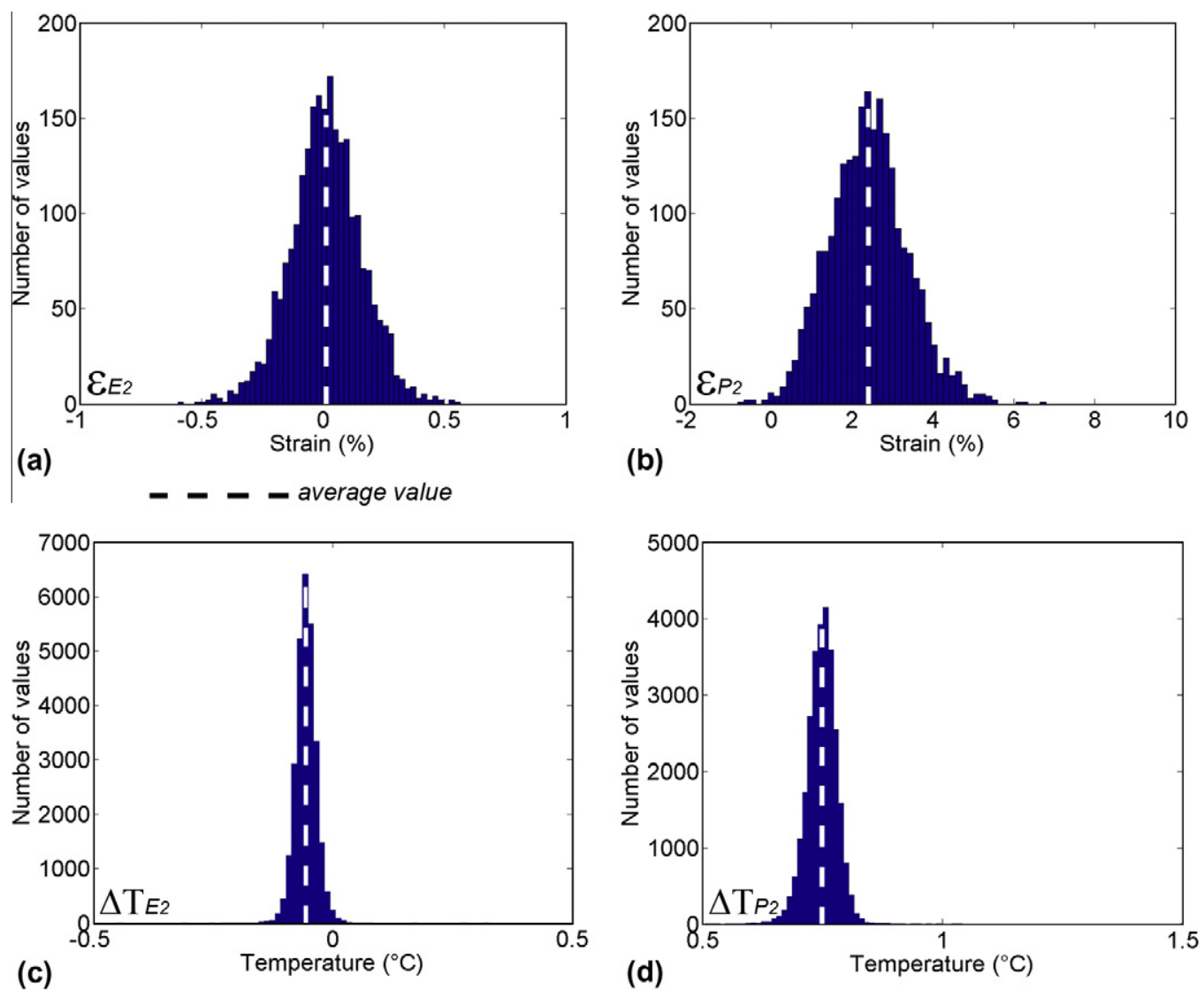

Fig. 12. Case of the $5 \times 10^{-3} \mathrm{~s}^{-1}$ test. Histograms of distribution of strains values over the $5 \mathrm{~mm} \times 5 \mathrm{~mm}$ fields at instants (a) $E_{2}$ under global elastic regime and (b) $P_{2}$ under global plastic regime. Histograms of distribution of temperature variation values over the $5 \mathrm{~mm} \times 5 \mathrm{~mm}$ fields at instants (c) $E_{2}$ and (d) $P_{2}$.

inside the squares in Fig. 13a and b), distinguishing features of strong plastic slip. Other grains show slighter slip marks, if any (cf. example inside the circles in Fig. 13a and b). The fact that some joints are highly visible (inside the triangles) means that the local deformation has been particularly intense. High deformation incompatibilities at the grain boundaries generate lattice rotations (Jaoul, 1965) and lead to the emergence of grains out of the surface in order to accommodate the deformation in the aggregate (hence the highly visible boundaries).

The out-of-plane displacement was further characterized by performing full-field 3D-profilometry with a Wyko NT 9300 from Veeco on the deformed samples after loading. The maximum out-of-plane displacement measured on both samples was close to $12 \mu \mathrm{m}$. Considering that no necking occurs given the amount of deformation applied to the sample, this can be the only possible source of out-of-plane motion. Since out-of-plane displacements are known to induce additional error on the planar strains measured by 2D-DIC, we used the equations derived by Sutton et al. (2008) to estimate the perturbation on the measured strains. In our case, the error arising from outof-plane displacements of magnitude smaller than $12 \mu \mathrm{m}$ is under $0.012 \%$ on in-plane strains, an order of magnitude less than the precision of the DIC itself. As far as infrared measurements are concerned, the fact that the coating is made of metallic powder creates a natural roughness that keeps the emissivity the same even if a slight out-of-plane motion slightly modifies the local orientation of the normal to the surface (Gaussorgues and Chomet, 1994). A careful examination of the coating after deformation did not reveal any noticeable 'orange-peel effect'. We thus neglected the effect of the deformation of the substrate below the coating on the strain and thermal measurements.

\subsection{Link between micrographs and final fields}

Both aforementioned micrographs are superimposed on the corresponding axial strain field in the loading direction at $P_{1}$ and $P_{2}$ (Figs. 14a and 15a, respectively) and on the fields of variation of temperature from the initial equilibrium at instants $P_{1}$ and $P_{2}$ (Figs. 14b and 15b, respectively). Fields at instants $P_{1}$ and $P_{2}$ correspond to the maximum stress applied to the sample, which comes just before unloading (267.5 MPa for the $5 \times 10^{-4} \mathrm{~s}^{-1}$ test and $268.6 \mathrm{MPa}$ for the $5 \times 10^{-3} \mathrm{~s}^{-1}$ test, respectively)-hence their superimposition with the post-mortem micrographs that correspond to the residual state of deformation. At $P_{1}$, 31 s have elapsed from the beginning of the test and at instant $P_{2}, 2$ s have elapsed.

Superimposing the deformed microstructure and the axial strain field in the loading direction (Figs. 14a and 
Table 1

Minimum, maximum, average strain and standard deviation for both tensile tests.

\begin{tabular}{|c|c|c|c|c|c|c|}
\hline $\begin{array}{l}\text { Rate of the } \\
\text { test }\left(s^{-1}\right)\end{array}$ & Field considered & $\begin{array}{l}\text { Minimum strain } \\
\varepsilon_{\min }(\%)\end{array}$ & $\begin{array}{l}\text { Maximum strain } \\
\varepsilon_{\max }(\%)\end{array}$ & $\begin{array}{l}\text { Average strain } \\
\varepsilon_{\text {avg }}(\%)\end{array}$ & $\begin{array}{l}\text { Standard deviation } \\
\varepsilon_{\text {std }}(\%)\end{array}$ & $\begin{array}{l}\text { Ratio standard deviation/ } \\
\text { average } \varepsilon_{\text {std }} / \varepsilon_{\text {avg }}\end{array}$ \\
\hline $5 \times 10^{-4}$ & $E_{1}$ & -0.79 & 0.73 & 0.03 & 0.18 & 5.55 \\
\hline $5 \times 10^{-4}$ & $P_{1}$ & -0.25 & 8.43 & 3.68 & 1.29 & 0.35 \\
\hline $5 \times 10^{-3}$ & $E_{2}$ & -0.59 & 0.55 & 0.01 & 0.15 & 10.65 \\
\hline $5 \times 10^{-3}$ & $P_{2}$ & -0.75 & 6.73 & 2.42 & 1.29 & 0.53 \\
\hline
\end{tabular}

Table 2

Minimum, maximum, average temperature variation and standard deviation for both tensile tests.

\begin{tabular}{|c|c|c|c|c|c|c|}
\hline $\begin{array}{l}\text { Rate of the } \\
\text { test }\left(s^{-1}\right)\end{array}$ & $\begin{array}{l}\text { Field } \\
\text { considered }\end{array}$ & $\begin{array}{l}\text { Minimum temperature } \\
\text { variation } \Delta T_{\min }\left({ }^{\circ} \mathrm{C}\right)\end{array}$ & $\begin{array}{l}\text { Maximum temperature } \\
\text { variation } \Delta T_{\max }\left({ }^{\circ} \mathrm{C}\right)\end{array}$ & $\begin{array}{l}\text { Average temperature } \\
\text { variation } \Delta T_{\text {avg }}\left({ }^{\circ} \mathrm{C}\right)\end{array}$ & $\begin{array}{l}\text { Standard deviation } \\
\Delta T_{\text {std }}\left({ }^{\circ} \mathrm{C}\right)\end{array}$ & $\begin{array}{l}\text { Ratio standard } \\
\text { deviation/average } \\
\Delta T_{\text {std }} / \Delta T_{\text {avg }}\end{array}$ \\
\hline $5 \times 10^{-4}$ & $E_{1}$ & -0.187 & -0.029 & -0.092 & 0.008 & 0.08 \\
\hline $5 \times 10^{-4}$ & $P_{1}$ & 0.703 & 0.973 & 0.886 & 0.026 & 0.03 \\
\hline $5 \times 10^{-3}$ & $E_{2}$ & -0.229 & 0.065 & -0.056 & 0.008 & 0.15 \\
\hline $5 \times 10^{-3}$ & $P_{2}$ & 0.584 & 0.881 & 0.748 & 0.021 & 0.03 \\
\hline
\end{tabular}
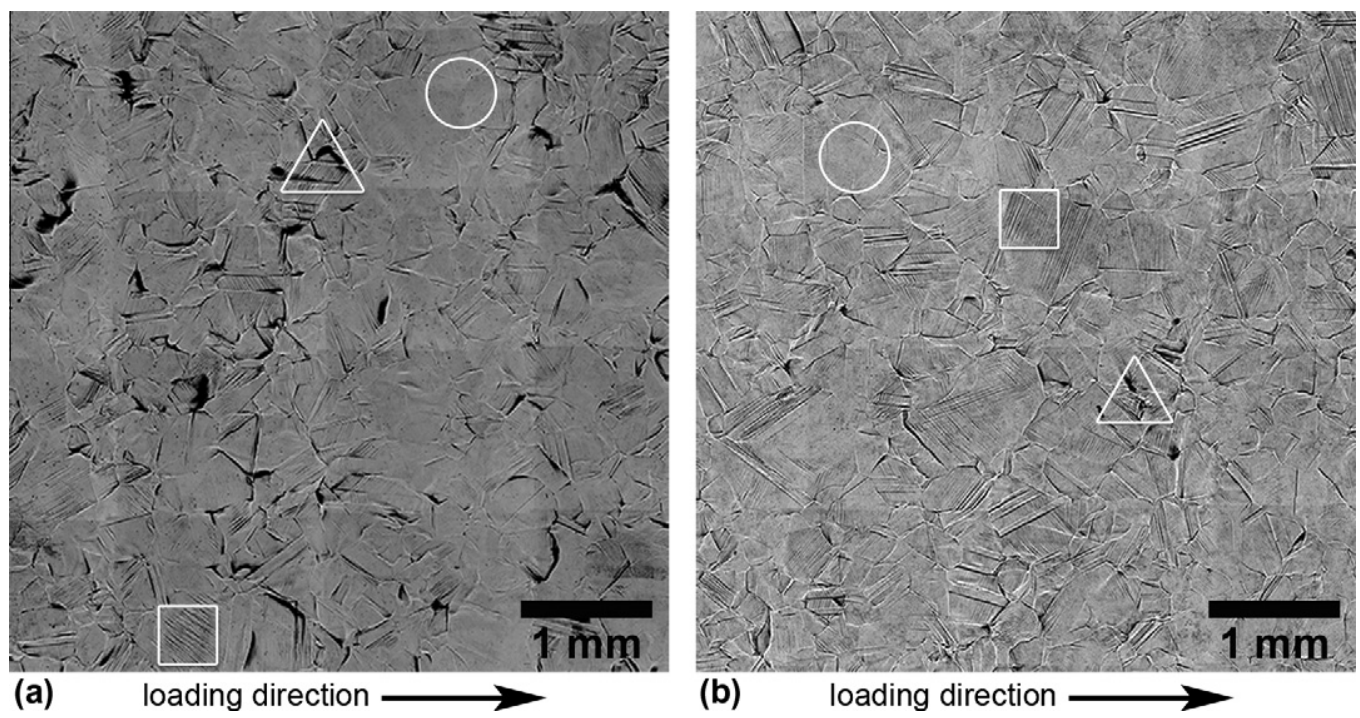

Fig. 13. Microstructure of the $5 \mathrm{~mm} \times 5 \mathrm{~mm}$ zone of interest obtained by optical microscope after loading and removal of the coating. (a) Sample loaded at $5 \times 10^{-4} \mathrm{~s}^{-1}$ and (b) sample loaded at $5 \times 10^{-3} \mathrm{~s}^{-1}$. Circles show an example of grains without marks; squares show an example of grains exhibiting heavy slip lines and triangles show an example of grain rotation.

15a) shows that the grains submitted to the highest levels of strain (e.g., inside the squares) exhibit very intense plastic slip. In particular, the highest strain values are found in areas where twins are present or where the lattice rotation was large (apparent grain boundaries). Conversely, small strains correspond to zones where the slip marks remain slight (e.g., inside the circles). The very heterogeneous features of the post-mortem surface are thus related to the sharp gradients exhibited by the strain field. This strong and direct link between the axial strain fields (captured just before unloading) and the deformed microstructure is due to the fact that a strain field at a given instance always corresponds to the cumulative deformation that the sample undergoes. Moreover, it can be noted that strain is not homogeneous within a grain. An example is given in the rectangle in Fig. 15a (enlarged in Fig. 15c): the bottom left of the rectangle exhibits an intensified strain in an area where double slip occurs and where a grain boundary is nearby.

The zones analyzed for the strain fields are reproduced in the image of the deformed microstructure superimposed with the fields of temperature variation from the initial equilibrium state in Figs. 14b and 15b. In the case of the $5 \times 10^{-3} \mathrm{~s}^{-1}$ test, the square zone corresponding to a high strain level also exhibits a higher temperature gradient (square in Fig. 15b) whereas the zone corresponding to a lower strain has a lower temperature gradient (circle in Fig. 15b). However, this relationship is not verified in the case of the slower test at $5 \times 10^{-4} \mathrm{~s}^{-1}$ (see the circle and square in Fig. 14b). When superimposing the 

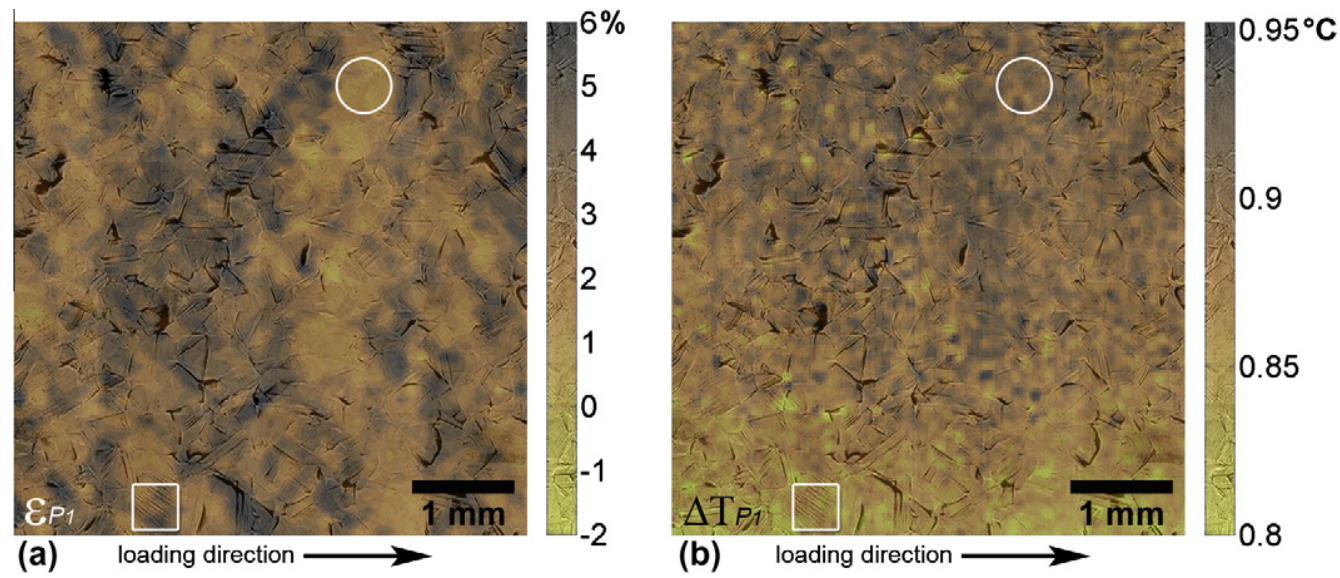

Fig. 14. Case of the $5 \times 10^{-4} \mathrm{~s}^{-1}$ test. Superimposition of the microstructure of Fig. 13a with (a) the strain field in the loading direction at instant $P_{1}$ and (b) the variation of temperature from the initial equilibrium at $P_{1}$.

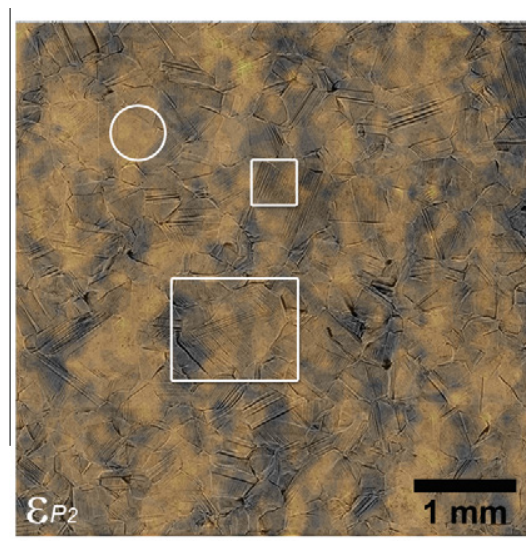

(a)
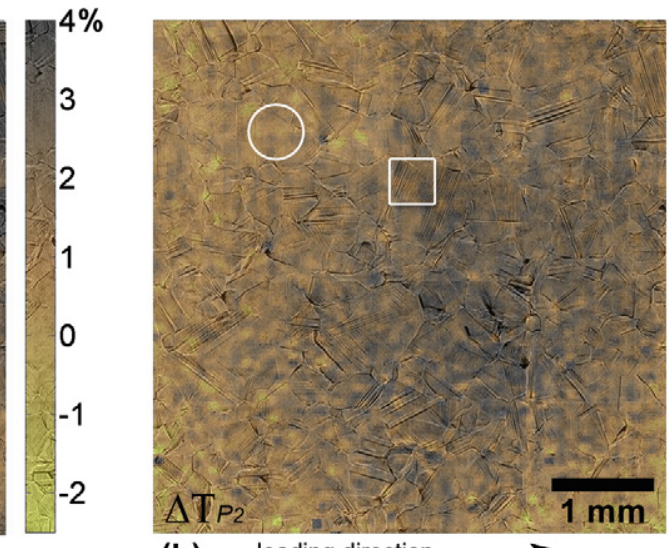

(b)

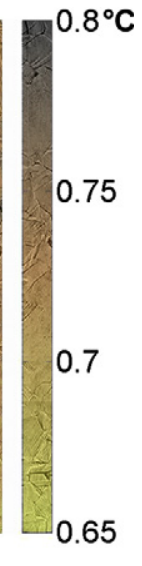

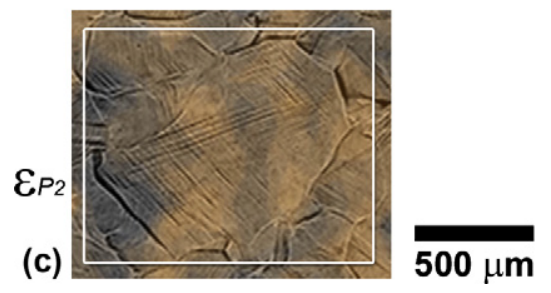

Fig. 15. Case of the $5 \times 10^{-3} \mathrm{~s}^{-1}$ test. Superimposition of the microstructure of Fig. 13b with (a) the strain field in the loading direction at instant $P_{2}$ and (b) the variation of temperature from the initial equilibrium at $P_{2}$. (c) Zoom on the rectangle of Fig. 15a.

post-mortem microstructure and the temperature gradient fields, one cannot expect the same kind of systematic relationship that was observed for the strain fields. As a matter of fact, even when-at the instance of capture-some heavily marked grains exhibit a higher temperature gradient (e.g. the square in Fig. 15b), thermal gradients triggered by thermomechanical coupling may also appear in grains with smaller strains. This is because, in both cases, dissipative mechanisms of slip are occurring at that moment. Similarly, a grain already exhibiting a high level of strain might not exhibit a high temperature gradient because no slip has occurred for awhile before the instance of capture. Contrary to strain (which is cumulative and carries the deformation history), temperature represents instantaneous information. Moreover, it is affected by thermal diffusion even if the 316L steel possesses a low thermal diffusivity $\left(0.4 \mathrm{~m}^{2} \mathrm{~s}^{-1}\right)$ compared with many other steels and aluminums (1.2 and $8.6 \mathrm{~m}^{2} \mathrm{~s}^{-1}$, respectively). These thermal exchanges are all the more significant when the strain rate is low. Hence there is a lack of systematic relationship between local high-temperature gradients and high-strain values observed in the case of the $5 \times 10^{-4} \mathrm{~s}^{-1}$ test, which is ten times slower than the second case presented in this study. Nevertheless, even if they are less sharp than that of the strain fields, the heterogeneities of the temperature fields appear at the grain scale. If 
we look at the scale of grain clusters, on the other hand, one can notice that the zones presenting the largest clusters of grains with high-strain levels can be associated with the highest temperature gradients. Once again, this phenomenon is more visible in Fig. 15b for the test conducted at a higher strain rate since it is less affected by thermal diffusion.

\subsection{Observation of dissipation triggered by a strain gradient at the grain scale}

In the previous section, it was seen that the fields of temperature variation at the last increment of loading show a relationship between high-strain and high-temperature gradients only at a relatively large scale, corresponding to grains clusters. This is despite the fact that temperature is an instantaneous form of data which does not directly account for the deformation history. In this section, we investigate the existence of an instantaneous link at the grain scale between deformation gradients and temperature gradients. For this purpose, we analyze two consecutive instances called $P_{2}^{\prime}$ and $P_{2}$ in the case of the $5 \times 10^{-3} \mathrm{~s}^{-1}$ test (see Fig. 8b). The strain fields and the corresponding fields of temperature variation from the initial equilibrium to $P_{2}^{\prime}$ and $P_{2}$ are presented in Fig. 16. Note that the strain fields at $P_{2}^{\prime}$ and $P_{2}$ (Fig. 16a and b) are plotted with the same scale and that the temperature gradient fields at $P_{2}^{\prime}$ and $P_{2}$ (Fig. 16c and d) are plotted with the same scale range.

Between $P_{2}^{\prime}$ and $P_{2}$, separated by $0.29 \mathrm{~s}$, a stress increment from $263.1 \mathrm{MPa}$ to $268.6 \mathrm{MPa}$ is applied to the whole sample. In the ZOI, some grains locally experience a strain increment. This can be seen, for example, in the zones marked by a thin and a bold circle; between Fig. 16a and b, the shades become darker, indicating an increase in the strain level. At the same instance, the color gradients in the corresponding circles in Fig. 16c and $\mathrm{d}$ become sharper and stronger with respect to the rest of the zone. This is the sign of a local temperature elevation in these locations. This observation introduces experimental evidence of how a strain gradient within a grain triggers simultaneously a thermal dissipation, translated into a temperature increase. As the sample is submitted to an increasing load, plasticity evolves locally, inducing heterogeneous strain gradients and triggering a concomitant thermal dissipation at the grain scale. This link between strains (elastic and plastic), dissipation and energy storage can be related to common knowledge in the field of granular materials as discussed by Collins (2005) and Nicot and Darve (2006).
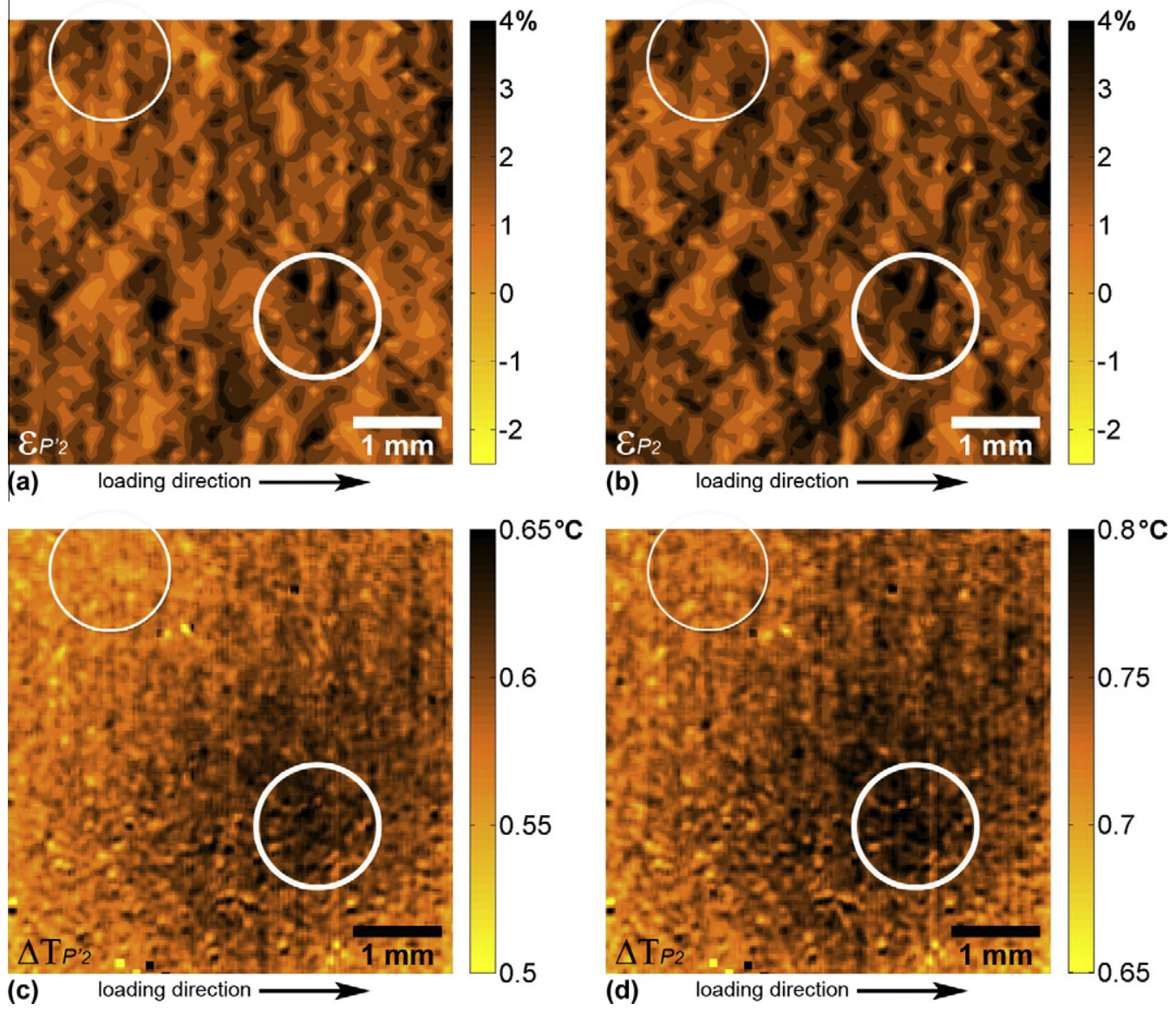

Fig. 16. Case of the $5 \times 10^{-3} \mathrm{~s}^{-1}$ test. Circles of same thickness on each fields show that increases in axial strain between (a) instant $P_{2}^{\prime}$ and (b) instant $P_{2}$ trigger simultaneously an increase in temperature between (c) instant $P_{2}^{\prime}$ and (d) instant $P_{2}$. 
3.6. Estimation of the fraction of plastic work dissipated into heat based on full-field measurements at the microstructure scale

The purpose of this section is not to establish an energy balance at the grain scale, since this task is a dedicated numerical challenge in its own right (Pottier, 2010). Instead, we aim to give the first 'rough' estimate of the dissipated energy field between instances $P_{2}^{\prime}$ and $P_{2}$ of the $5 \times 10^{-3} \mathrm{~s}^{-1}$ test. We introduce the equation for the fraction of plastic work converted into heat, also well-known as the $\beta$ ratio, as

$\beta=\frac{\rho C_{p} \dot{T}}{\sigma_{i j} \dot{\varepsilon}_{i j}^{p}}$

where $\rho$ is the material density, $C_{p}$ is the specific heat at constant pressure, $\dot{T}$ is the rate of change of temperature, $\sigma_{i j}$ is the stress field and $\dot{\epsilon}_{i j}^{p}$ is the plastic strain rate field.

As detailed in Hodowany et al. (2000), Eq. (4) is derived from the energy balance equation under the assumptions that the process is adiabatic and that plastic deformation prevails. As a result, in our case we have to assume both that the process is adiabatic during the $0.29 \mathrm{~s}$ separating $P_{2}^{\prime}$ from $P_{2}$, and that plastic deformation is predominant at this stage of the loading. Under these assumptions, we can estimate a differential $\beta$ field by calculating each term as follows:

- $\rho$ and $C_{p}$ are taken as constants over the considered fields, equal to the bulk values of $8000 \mathrm{~kg} \mathrm{~m}^{-3}$ and $500 \mathrm{~J} \mathrm{~kg}^{-1} \mathrm{~K}^{-1}$, respectively.

- $\dot{T}$ is the difference of the thermal gradient fields between $P_{2}^{\prime}$ and $P_{2}$. In Eq. (4), no indices appear in $\dot{T}$ because temperature is usually considered a global value. However, we are actually considering a field, so $\dot{T}=\dot{T}_{i j}$.

- $\sigma_{i j}$ is evaluated as $\sigma_{\text {int }}+E_{p} \varepsilon_{i j}^{t}$, where the field $\varepsilon_{i j}^{t}$ is taken to be the average value of the total axial strain fields at $P_{2}^{\prime}$ and $P_{2}$. In this expression, $E_{p}$ is the plastic modulus and $\sigma_{\text {int }}$ is the $y$-intercept (the global behavior of the material is assumed to be bi-linear). Both $E_{p}$ and $\sigma_{\text {int }}$ are determined through a least-squares approximation of the stress-strain curve built from the results presented in Fig. 8b. They are calculated to be $218 \mathrm{MPa}$ and $21.57 \mathrm{GPa}$, respectively. Note that we assume that the local stress field $\sigma_{\text {int }}$ is equivalent to a macroscopic stress since we cannot access local stresses experimentally nor do we infer any constitutive law at this scale.

- $\dot{\varepsilon}_{i j}^{p}$ is taken as $\Delta \dot{\varepsilon}_{i j}^{t}$ which is the difference of the total axial strain fields between $P_{2}^{\prime}$ and $P_{2}$ under the assumption that plastic deformation prevails and that plastic strain can be approximated by the total strain.

The estimation of a $\beta$ ratio field is thus obtained as described above, with strain and temperature gradient fields at $P_{2}^{\prime}$ and $P_{2}$ smoothed out before input into Eq. (4). The result is plotted in Fig. 17 where the estimated $\beta$ ratio field appears to be heterogeneous. Although the input data was smoothed, the resulting heterogeneities seem to cover grain clusters rather than individual grains. The highest values are located over clusters that exhibit the least

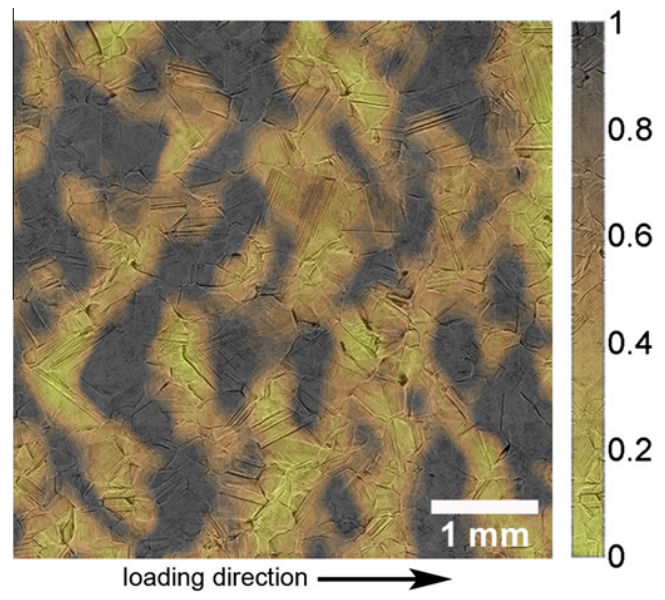

Fig. 17. First estimation of the differential $\beta$ ratio field between instants $P_{2}^{\prime}$ and $P_{2}$ of the $5 \times 10^{-3} \mathrm{~s}^{-1}$ test.

amount of slip marks. This indicates that in these zones, the plastic work is highly dissipated into heat. Conversely, heavily marked zones or clusters tend to show low values of the $\beta$ ratio which means that most of the plastic work is stored and thusly invested into microstructural changes (Bever et al., 1973; Farren and Taylor, 1925). This result is an approximation of a field of fraction of plastic work converted into heat ( $\beta$ ratio) at the grain scale, only insofar as the assumptions that are made. Nonetheless, it gives for the first time a glimpse of the heterogeneity of energy quantities at the microstructural scale. It further supports the idea that performing energy balances at the grain scale could be of great interest in the future. An estimation of a $\beta$ ratio field and its evolution in time could lead to the definition of localization and damage criteria based on energy quantities. This is assuming, of course, that the many numerical issues are overcome, such as the difficulty of extracting the plastic strain from the measured total strain, or the difficulty in resolving the discontinuities that appear in any derivative (due to the heterogeneities over a few pixels).

\section{Conclusions}

In this paper, fully-coupled full-field kinematic and thermal measurements are performed in-situ and in realtime at the microstructural scale of an austenitic stainless steel under quasi-static tensile loading, using a unique experimental setup and a data processing algorithm. The obtained fields are correlated to the microstructural marks of plasticity that emerge at the surface of the sample. The kinematic and thermal fields observed during a plastic tensile deformation are definitely not homogeneous between grains (nor even within a single grain), owing to the polycrystalline nature of the studied material. Evidence of local plasticity appears under a load that gives rise to global elastic deformation, and the degree of heterogeneity of the strain fields decreases as the plastic deformation increases.

A direct link has been established at the grain scale between plastic deformation and the appearance of slip 
marks at the surface of the sample. Low levels of deformation are correlated to few-to-no slip marks at the surface. At the last load increment, a link has been also established between high levels of strains and localization of the thermal dissipation. The latter is not cumulative like strains and is affected by thermal diffusion within the material. The relationship between high-strain and high-temperature is only valid at the larger lengthscale of grains clusters.

This study also provides an experimental observation of thermal dissipation triggered by a strain gradient at the grain scale, proving that thermomechanical couplings take place as far down as the grain level. Additionally, a first approximation of a field of fraction of plastic work converted into heat was conducted at the microstructural level and related to the microstructural features of deformation across hundreds of grains. The heterogeneous kinematic, thermal and energy data presented in this study not only confirm that the behavior of a polycrystal is strongly different from one grain to the other, but also show that the energy balance can be expected to be different from grain to grain (even with small local temperature variation). Therefore, in our opinion, establishing fields of energy balance at the grain scale from experimentally obtained heterogeneous (albeit discrete and noisy) data could give precious information about the microstructural evolutions undergone by polycrystals during deformation, possibly giving rise to an energy-based damage indicator. We acknowledge, however, that this is a numerical challenge as evidenced in attempts on more macroscopic data (Berthel et al., 2008; Chrysochoos and Louche, 2000; Louche, 1999). In an even broader perspective, the relationship between the local values of the ratio of plastic work converted into heat and grain orientation data from EBSD could be of great interest as far as understanding damage of metallic polycrystalline materials. The attempt to use the data presented in this study to establish energy balances at the grain scale of the polycrystal is currently under investigation.

Finally, we would like to mention that determining 3D orientations (involving heavy experimental resources such as synchrotron) (Ludwig et al., 2008), combined with 3D thermal and strain measurements, would provide a better understanding of how grains in the third direction contribute to the whole response of the polycrystal. Similarly, if high-speed acquisitions and high resolutions were to become compatible, conducting the experiments developed in this paper under dynamic loading would give insight into phenomena for which a high temperature rise affects the behavior of a material, as in the case of adiabatic shear banding.

\section{Acknowledgements}

This study has been funded by the CNRS, the NordPas-de-Calais area (CISIT) and the European Community (FEDER). The authors would like to acknowledge the CNRS Research Group GDR's 2519 "Full-field measurements and Identification in Solid Mechanics" as well as François Hild (LMT, Cachan) for his valuable advice about the software Correli $^{\text {LMT }}$. LB also thanks Daniel Rittel for their fruitful discussions.

\section{References}

Badulescu, C., Grédiac, M., Haddadi, H., Mathias, J.D., Balandraud, X., Tran, H.S., 2011. Applying the grid method and infrared thermography to investigate plastic deformation in aluminium multicrystal. Mech. Mater. 43, 36-53.

Bagi, K., 1996. Stress and strain in granular assemblies. Mech. Mater. 22, 165-177.

Berthel, B., Chrysochoos, A., Wattrisse, B., Galtier, A., 2008. Infrared image processing for the calorimetric analysis of fatigue phenomena. Exp. Mech. 48, 79-90.

Berthel, B., Wattrisse, B., Chrysochoos, A., Galtier, A., 2007. Thermographic analysis of fatigue dissipation properties of steel sheets. Strain 43, 273-279.

Bever, M.B., Holt, D.L., Titchener, A.L., 1973. The stored energy of cold work. Prog. Mater. Sci. 17, 5-88.

Bodelot, L., 2008. Etude couplée des champs cinématiques et thermiques à l'échelle de la microstructure des matériaux métalliques. PhD Thesis, Université des Sciences et Technologies de Lille I.

Bodelot, L., Sabatier, L., Charkaluk, E., Dufrénoy, P., 2009. Experimental setup for fully coupled kinematic and thermal measurements at the microstructure scale of an AISI 316L steel. Mater. Sci. Eng. A 501, 5260.

Chrysochoos, A., Louche, H., 2000. An infrared image processing to analyse the calorific effects accompanying strain localisation. Int. J. Eng. Sci. 38, 1759-1788.

Chrysochoos, A., Muracciole, J.M., Watrisse, B., 2000. Experimental analysis of strain and damage localization. Continuous Damage and Fracture, Cachan, France, pp. 41-51.

Collins, I.F., 2005. The concept of stored plastic work of frozen elastic energy in soil mechanics. Géotechnique 55, 373-382.

Efstathiou, C., Sehitoglu, H., Lambros, J., 2010. Multiscale strain measurements of plastically deforming polycrystalline titanium: role of deformation heterogeneities. Int. J. Plast. 26, 93-106.

El Bartali, A., Aubin, V., Degallaix, S., 2007. Fatigue damage analysis in a duplex stainless steel by digital image correlation technique. Fatigue Fract. Eng. Mater. Struct. 31, 137-151.

Evrard, P., El Bartali, A., Aubin, V., Rey, C., Degallaix, S., Kondo, D., 2010. Influence of boundary conditions on bi-phased polycrystal microstructure calculation. Int. J. Solids Struct. 47, 1979-1986.

Farren, W.S., Taylor, G.I., 1925. The heat developed during plastic extension of metals. Proc. R. Soc. Lond. Ser. A 107, 422-451.

Friedel, J., 1964. Dislocations. Pergamon Press, Oxford.

Gaussorgues, G., Chomet, S., 1994. Infrared Thermography. Chapman \& Hall, London.

Goldenberg, C., Goldhirsch, I., 2002. Force chains, microelasticity, and macroelasticity. Phys. Rev. Lett. 89, 084302.

Guduru, P.R., Rosakis, A.J., Ravichandran, G., 2001. Dynamic shear bands: an investigation using high speed optical and infrared diagnostics. Mech. Mater. 33, 371-402.

Hild, F., 2002. Correli ${ }^{\text {LMT }}$ : a software for displacement field measurements by digital image correlation. Internal Report No. 254, LMT-Cachan, France.

Hild, F., Raka, B., Baudequin, M., Roux, S., Cantelaube, F., 2002. Multiscale displacement field measurements of compressed mineral-wool samples by digital image correlation. Appl. Opt. 41, 6815-6828.

Hodowany, J., Ravichandran, G., Rosakis, A., Rosakis, P., 2000. Partition of plastic work into heat and stored energy in metals. Exp. Mech. 40, 113-123.

Horny, N., 2003. FPA camera standardisation. Infrared Phys. Technol. 44, 109-119.

Jaoul, B., 1965. Étude de la plasticité et application aux métaux, Dunod, Paris.

Kruyt, N.P., Rothenburg, L., 2006. Shear strength, dilatancy, energy and dissipation in quasi-static deformation of granular materials. J. Stat. Mech: Theory Exp. 2006, P07021.

Lance, G.L., Nemat-Nasser, S., 1986. Slip-induced plastic flow of geomaterials and crystals. Mech. Mater. 5, 1-11.

Lemaitre, J., Chaboche, J.L., 1988. Mechanics of Solid Materials. Cambridge University Press.

Louche, H., 1999. Analyse par thermographie infrarouge des effets dissipatifs de la localisation dans les aciers. PhD Thesis, Université de Montpellier II Sciences et Techniques du Languedoc.

Louche, H., Chrysochoos, A., 2001. Thermal and dissipative effects accompanying Lüders band propagation. Mater. Sci. Eng. A 307, 15-22.

Ludwig, W., Schmidt, S., Lauridsen, E.M., Poulsen, H.F., 2008. X-ray diffraction contrast tomography: a novel technique for threedimensional grain mapping of polycrystals. I - Direct beam case. J. Appl. Crystallogr. 41, 302-309. 
Macherauch, E., 1966. X-ray stress analysis. Exp. Mech. 6, 140-153.

Nicot, F., Darve, F., RNVO Group: Natural Hazards and Vulnerability of Structures, 2005. A multi-scale approach to granular materials. Mech. Mater. 37, 980-1006.

Nicot, F., Darve, F., 2006. On the elastic and plastic strain decomposition in granular materials. Granul. Matter 8, 221-237.

Osterstock, S., Robertson, C., Sauzay, M., Degallaix, S., Aubin, V., 2007. Prediction of the scatter of crack initiation under high cycle fatigue. Key Eng. Mater., 363-366.

Ostoja-Starzewski, M., 1993. Random fields and processes in mechanics of granular materials. Mech. Mater. 16, 55-64.

Pottier, T., 2010. Identification paramétrique par recalage de modèles éléments finis couplée à des mesures de champs cinématiques et thermiques. PhD Thesis, Université de Savoie.

Rittel, D., Bhattacharyya, A., Poon, B., Zhao, J., Ravichandran, G., 2007. Thermomechanical characterization of pure polycrystalline tantalum. Mater. Sci. Eng. A 447, 65-70.

Saai, A., Louche, H., Tabourot, L., Chang, H.J., 2010. Experimental and numerical study of the thermo-mechanical behavior of Al bi-crystal in tension using full field measurements and micromechanical modeling. Mech. Mater. 42, 275-292.
Sauzay, M., 2006. Effet de l'anisotropie élastique cristalline sur la distribution des facteurs de Schmid à la surface des polycristaux. C.R. Mec. 334, 353-361.

Sobrino, J.A., Cuenca, J., 1999. Angular variation of thermal infrared emissivity for some natural surfaces from experimental measurements. Appl. Opt. 38, 3931-3936.

Stroh, A.N., 1953. A theoretical calculation of the stored energy in a workhardened material. Proc. R. Soc. Lond. Ser. A 218, 391-400.

Sutton, M.A., Yan, J.H., Tiwari, V., Schreier, H.W., Orteu, J.J., 2008. The effect of out-of-plane motion on 2D and 3D digital image correlation measurements. Opt. Lasers Eng. 46, 746-757.

Taylor, G.I., 1938. Plastic strains in metals. J. Inst. Metals 62, 307-324.

Taylor, G.I., Quinney, H., 1933. The latent energy remaining in a metal after cold working. Proc. R. Soc. Lond. Ser. A 143, 307-326.

Walsh, S., Tordesillas, A., Peters, J., 2007. Development of micromechanical models for granular media. Granul. Matter 9, 337352.

Wang, W.-J., Kong, X.-Z., Zhu, Z.-G., 2007. Friction and relative energy dissipation in sheared granular materials. Phys. Rev. E 75, 041302. 